ARTICLE

https://doi.org/10.1038/s41467-020-14567-8

\title{
Minimally disruptive optical control of protein tyrosine phosphatase $1 \mathrm{~B}$
}

Akarawin Hongdusit ${ }^{1}$, Peter H. Zwart ${ }^{2}$, Banumathi Sankaran ${ }^{2} \&$ Jerome M. Fox (i) ${ }^{1 \star}$

Protein tyrosine phosphatases regulate a myriad of essential subcellular signaling events, yet they remain difficult to study in their native biophysical context. Here we develop a minimally disruptive optical approach to control protein tyrosine phosphatase 1B (PTP1B) - an important regulator of receptor tyrosine kinases and a therapeutic target for the treatment of diabetes, obesity, and cancer-and we use that approach to probe the intracellular function of this enzyme. Our conservative architecture for photocontrol, which consists of a protein-based light switch fused to an allosteric regulatory element, preserves the native structure, activity, and subcellular localization of PTP1B, affords changes in activity that match those elicited by post-translational modifications inside the cell, and permits experimental analyses of the molecular basis of optical modulation. Findings indicate, most strikingly, that small changes in the activity of PTP1B can cause large shifts in the phosphorylation states of its regulatory targets. 
T he enzymatic phosphorylation of tyrosine residues is centrally important to cellular function. It controls the location and timing of cellular differentiation, movement, proliferation, and death ${ }^{1-4}$; its misregulation can cause cancer, diabetes, and neurodegenerative diseases, among other disorders $^{5-7}$. Methods to control the activity of phosphorylationregulating enzymes without interfering with their native structure or cellular organization could, thus, enable detailed analyses of the mechanisms by which cells process essential chemical signals ${ }^{8,9}$.

Optogenetic actuators-genetically encoded proteins that undergo light-induced changes in conformation-provide a powerful means of controlling enzyme activity over time and space. As protein fusion partners, they have enabled optical manipulation of biomolecular transport, binding, and catalysis with millisecond and submicron resolution ${ }^{10,11}$. Common strategies to integrate optogenetic actuators into enzymes include (i) attachment near an active site, where they control substrate access $^{12,13}$, (ii) insertion within a catalytic domain, where they afford activity-modulating structural distortions ${ }^{14}$, and (iii) fusion to $\mathrm{N}$ - or C-termini, where they direct subcellular localization ${ }^{15}$ or guide domain assembly ${ }^{16}$. These approaches have generated powerful tools for stimulating phosphorylation-mediated signaling networks; unfortunately, their reliance on disruptive structural modifications has tended to limit their use in biochemical studies of native regulatory effects, for example, spatially dependent protein-protein interactions or, more notably, shifts in activity that match, rather than artificially exceed, those caused by post-translational modifications of an enzyme under study.

Protein tyrosine phosphatase 1B (PTP1B) is an important regulatory enzyme for which minimally disruptive architectures for photocontrol could prove particularly informative. This enzyme, which catalyzes the hydrolytic dephosphorylation of tyrosine residues, helps regulate insulin, leptin, and epidermal growth factor signaling and participates in a diverse set of spatiotemporally complex signaling processes ${ }^{17}$. PTP1B has two intriguing biophysical traits that make it particularly amenable to optogenetic study: (i) Its catalytically essential WPD loop undergoes cyclic, open-and-close motions that control the rate of phosphotyrosine hydrolysis at the active site ${ }^{18}$, and its C-terminal a7 helix modulates these motions through an allosteric network that extends over $25 \AA$ across the protein (Fig. 1a). An architecture for photocontrol that makes use of this network could afford changes in activity that preserve interactions between PTP1B and its regulatory targets. (ii) PTP1B undergoes several post-translational modifications outside of its active site that cause modest, yet physiologically influential shifts in its activity (i.e., 1.7-3.1-fold ${ }^{19,20}$; Supplementary Table 1). An optogenetic construct that affords similar changes in activity could help determine whether or not they-rather than the specific posttranslational modifications that cause them-are sufficient to influence cellular physiology.

In this study, we used a protein-based light switch to place the native allosteric regulatory system of PTP1B under optical control. This conservative optogenetic design preserved the native structure and subcellular localization of PTP1B, permitted changes in activity that match those caused by post-translational modifications inside the cell and, when paired with a FRET-based biosensor, enabled spatiotemporal control and measurement of intracellular PTP1B activity. An optogenetic analysis carried out with this system showed that small, transient changes in PTP1B activity can cause large shifts in insulin receptor (IR) phosphorylation. The optogenetic tools developed in this study thus complement existing methods for studying protein tyrosine kinases (PTKs) - which, unlike PTPs, possess many light-sensitive analogs and FRET-based biosensors ${ }^{21,22}$-and, more broadly, demonstrate an optogenetic approach for studying regulatory enzymes in their native biophysical context.

\section{Results}

Allosteric photocontrol of PTP1B. We sought to place PTP1B under optical control by using LOV2, the light-sensitive domain from phototropin 1 of Avena sativa, to toggle the conformation of its $\alpha 7$ helix. LOV2 derives its optical activity from a noncovalently bound flavin mononucleotide (FMN) that, when exposed to blue light, forms an intermolecular carbon-sulfur bond that destabilizes the N- and C-terminal helices of the protein (Fig. 1a ${ }^{23}$. We hypothesized that attachment of the N-terminal A'a helix of LOV2 to the C-terminal $\alpha 7$ helix of PTP1B would couple (i) lightinduced unwinding of the A'a helix to (ii) destabilization of the $\alpha 7$ helix and disruption of WPD loop motions (Fig. 1b). To our satisfaction, several PTP1B-LOV2 chimeras-each generated by fusing the $A^{\prime} \alpha$ and $\alpha 7$ helices at a different crossover point in a primary sequence alignment-exhibited light-dependent catalytic activity on 4-methylumbelliferyl phosphate (4MUP; Fig. 1c). Fusion of the Ja helix of LOV2 to the N-terminus of PTP1B, by contrast, did not confer photosensitivity (Supplementary Figs. 1a, b), a result consistent with the large distance between its $\mathrm{N}$ terminus and active site (Fig. 1a).

To enhance the dynamic range $\left(\mathrm{DR}=\mathrm{V}_{\mathrm{o} \text {-dark }} / \mathrm{V}_{\mathrm{o} \text {-light }}\right)$ of our most light-sensitive chimera (i.e., construct 7 , where $\mathrm{DR}=1.9$ ), we used two approaches: First, we attempted to improve communication between the LOV2 and PTP1B domains by reducing the length of the linker between them; similar changes have improved photoswitching in other light-sensitive fusions ${ }^{24}$. Unfortunately, shorter linkers (which, through residue deletions, could also alter the phases of the fused helices) tended to reduce DR; we chose one variant with an unaltered DR-chimera 7.1-for further optimization. Next, we attempted to increase the stability of the dark state over the light state by adding stabilizing mutations to flexible helices. (For the Ja and A'a helices, we used established stabilizing mutaitons ${ }^{23,25}$; for $a 7$, we replaced solvent-exposed residues with alanine, which has a high helix propensity ${ }^{26}$ ). Stabilizing mutations in the Ja helix have amplified DRs of previous LOV2 fusions $s^{25,27}$. Intriguingly, for our chimeras, mutations in the Ja helix improved activity, but reduced photosensitivity; several mutations in the A'a and $\alpha 7$ helices, by contrast, increased the DR (Fig. 1c). Overall, the effects of amino acid substitutions in these two helices were nonadditive and reached a maximum DR of 2.2 on 4MUP. We chose a single high-DR chimera-7.1(T406A), termed $\mathrm{PTP}_{\mathrm{B}} \mathrm{B}_{\mathrm{PS}}-$ for further study.

We assessed the structural integrity of the PTP1B domain within PTP $1 \mathrm{~B}_{\mathrm{PS}}$ by using X-ray crystallography to examine its dark-state conformation. Intriguingly, although crystals of $\mathrm{PTP}_{\mathrm{B}} \mathrm{B}_{\mathrm{PS}}$ were yellow and turned clear when exposed to blue light - a behavior indicative of the presence of LOV2 ${ }^{12,28}$ diffraction data permitted placement and refinement of only PTP1B (Supplementary Figs. 2 and 3). Detection of LOV2 was likely impeded by two interrelated crystallographic features: (i) a disordered $\alpha 7$ helix, which is unresolvable in apo structures of $\mathrm{PTP}^{2} \mathrm{~B}^{29}$, and (ii) variability in the orientation of LOV2 within the crystal lattice (Supplementary Note 1). Despite this structural disorder, aligned catalytic domains of PTP1 $\mathrm{B}_{\mathrm{PS}}$ and wild-type PTP1B had a root-mean-square deviation of $0.30 \AA$ (Fig. 1d). Crystallographic results, thus, suggest that LOV2 does not alter the native conformation of the catalytic domain of PTP1B.

We explored the mechanism of photomodulation by using kinetic assays to examine the influence of LOV2 on PTP1Bmediated catalysis. In brief, we measured the activity of PTP $1 \mathrm{~B}_{\mathrm{PS}}$ on p-nitrophenyl-phosphate (pNPP) in the presence and absence of blue light $(455 \mathrm{~nm})$, and we used the initial rates to construct 


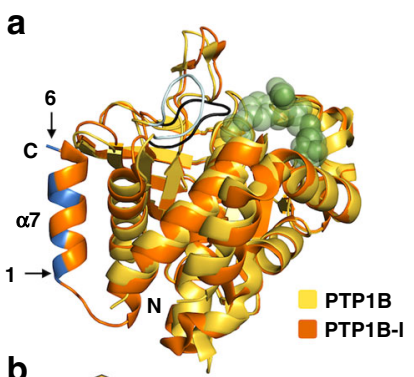

b

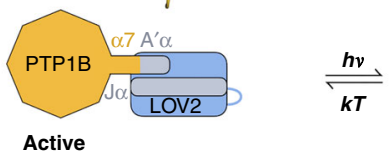

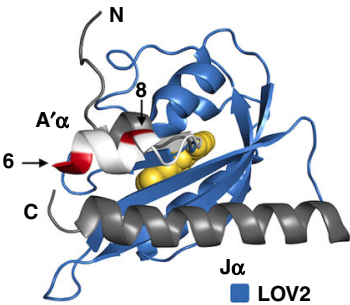

Lov2
C
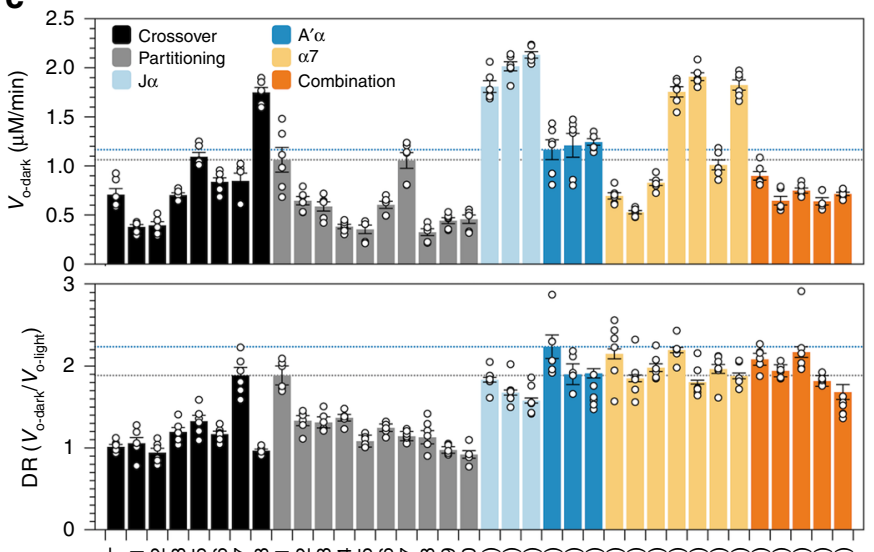

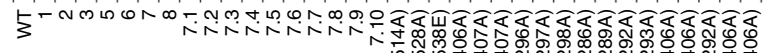

f

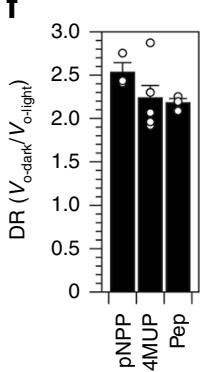

g
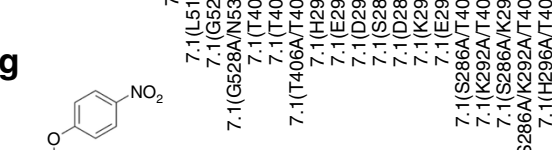

pNPP

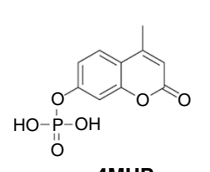

4MUP
离
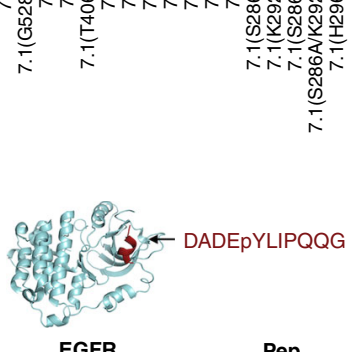

d

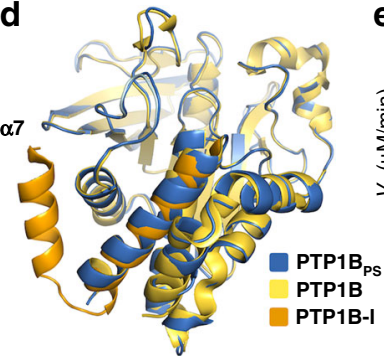

e

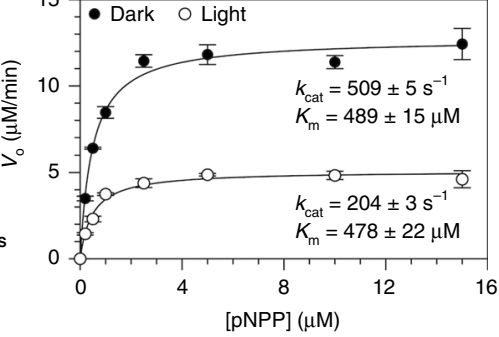

Fig. 1 Minimally disruptive photocontrol of PTP1B. a Left: An alignment of a competitively inhibited structure of PTP1B (orange, pdb entry 2f71) and an apo structure of PTP1B (yellow, pdb entry 3a5j) highlights an allosteric control system. Closure of the WPD loop (black) over an inhibitor orders the $\alpha 7$ helix; opening of the loop (light blue) hinders this ordering. Right: An alignment of the LOV2 domain from A. sativa (blue) and an N-terminal segment of the same domain of $A$. thaliana (white) that is identical between the two proteins (pdb entries $2 \mathrm{v} 0 \mathrm{w}$ and $4 \mathrm{hhd}$, respectively). Two terminal $\alpha$-helices (gray and white) are stable in the dark state, but not the light state. b Design of a photoswitchable chimera. Light-induced unwinding of the A' $\alpha$ helix of LOV2 destabilizes the $\alpha 7$ helix of PTP1B, causing an allosteric conformational change that inhibits catalysis. We attached the C-terminal $\alpha 7$ helix of PTP1B to the $\mathrm{N}$-terminal $\mathrm{A}^{\prime} \alpha$ helix of LOV2 at crossover points in a primary sequence alignment (1-8). These points are highlighted in blue (PTP1B) and red (LOV2) in (a). c Assays on 4-methylumbelliferyl phosphate (4MUP) show the results of chimera optimization. Construct 7 has the largest dynamic range (DR) of the

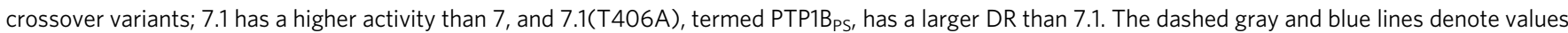
for 7.1 and 7.1(T406A), respectively. The plotted data depict the mean, SE, and associated estimates of DR for $n=6$ independent experiments. $\mathbf{d}$ Aligned catalytic domains of PTP1B in three structures: photoswitchable ( $6 \mathrm{ntp})$, apo (3a5j), and competitively inhibited (2f71, $\alpha 6$ and $\alpha 7$ only). e An analysis of the activity of PTP1B $B_{P S}$ on p-nitrophenyl-phosphate (pNPP) indicates that light affects $k_{\text {cat, }}$ but not $k_{m}\left(k_{\text {cat-dark }} / k_{\text {cat-light }}=2.50 \pm 0.04\right)$. Error bars denote SE for $n=3$ independent reactions. $\mathbf{f}$ The DR of PTP1BPs is similar for substrates of different sizes. The plotted data depict the mean, SE, and associated estimates of DR for $n \geq 3$ independent reactions. $\mathbf{g}$ Structures of pNPP, 4MUP, and a peptide (PEP) derived from epidermal growth factor receptor (EGFR). Source data are provided as a Source Data file.

dark- and light-state Michaelis-Menten curves (Fig. 1e). These curves indicate that blue light reduces $k_{\text {cat }}$ by 2.5 -fold but leaves $K_{\mathrm{m}}$ unaltered. Data collected under repeated illumination, in turn, shows that changes in $k_{\text {cat }}$ are reversible (Supplementary Fig. $4 \mathrm{c}$ ). The isolated influence of LOV2 on $k_{\text {cat }}$ indicates that this photoswitch does not interfere with substrate binding and, importantly, is consistent with a mechanism in which LOV2 allosterically modulates WPD loop motions, which control the rate of hydrolysis ${ }^{18}$.

To assess the maximum achievable DR for our system, we removed the $\alpha 7$ helix of PTP1B; that is, we used an $\alpha$ 7-less variant as a model for a maximally photoswitched form of the enzyme. Intriguingly, helix removal lowered $k_{\text {cat }}$ by 2.9 -fold, suggesting that PTP1B 1 has a DR that is $85 \%$ of the maximum value for a photoswitch that inhibits catalytic activity by unwinding the $\alpha 7$ helix (Supplementary Figs. 4a, b). Importantly, this DR is within the range of DRs of previously developed light-sensitive signaling enzymes used to elicit physiologically relevant cellular responses to optical stimuli (DRs 1.7-10 12,30; Supplementary Table 8 ) and matches physiologically influential changes in activity caused by post-translational modifications of PTP1B that occur outside of its active site (i.e., phosphorylation, proteolysis, and sumoylation, which reduce/enhance PTP1B activity by $1.7-3.1$-fold $^{19,20}$; Supplementary Table 1).

We hypothesized that an optogenetic system that exerts allosteric control over catalytically essential loop motions might-in contrast with a system that competitively inhibits the active site-exhibit a modulatory effect that is independent of substrate size and binding affinity. To test the substrate dependence of PTP1B $\mathrm{B}_{\mathrm{PS}}$, we measured its DR on pNPP, 4MUP, and a phosphorylated peptide (Fig. 1f). The DRs for these substrates differed by $<15 \%$ (Fig. 1g); this similarity suggests that the magnitude of photocontrol is, in fact, substrate independent.

Biophysical analysis of photocontrol. Although we designed our chimeras to exploit conformational changes in the N-terminal A'a helix of LOV2, the results of crystallographic and spectroscopic analyses of this photoswitch indicate that its $\mathrm{N}$ - and C-terminal helices work together to transduce conformational 

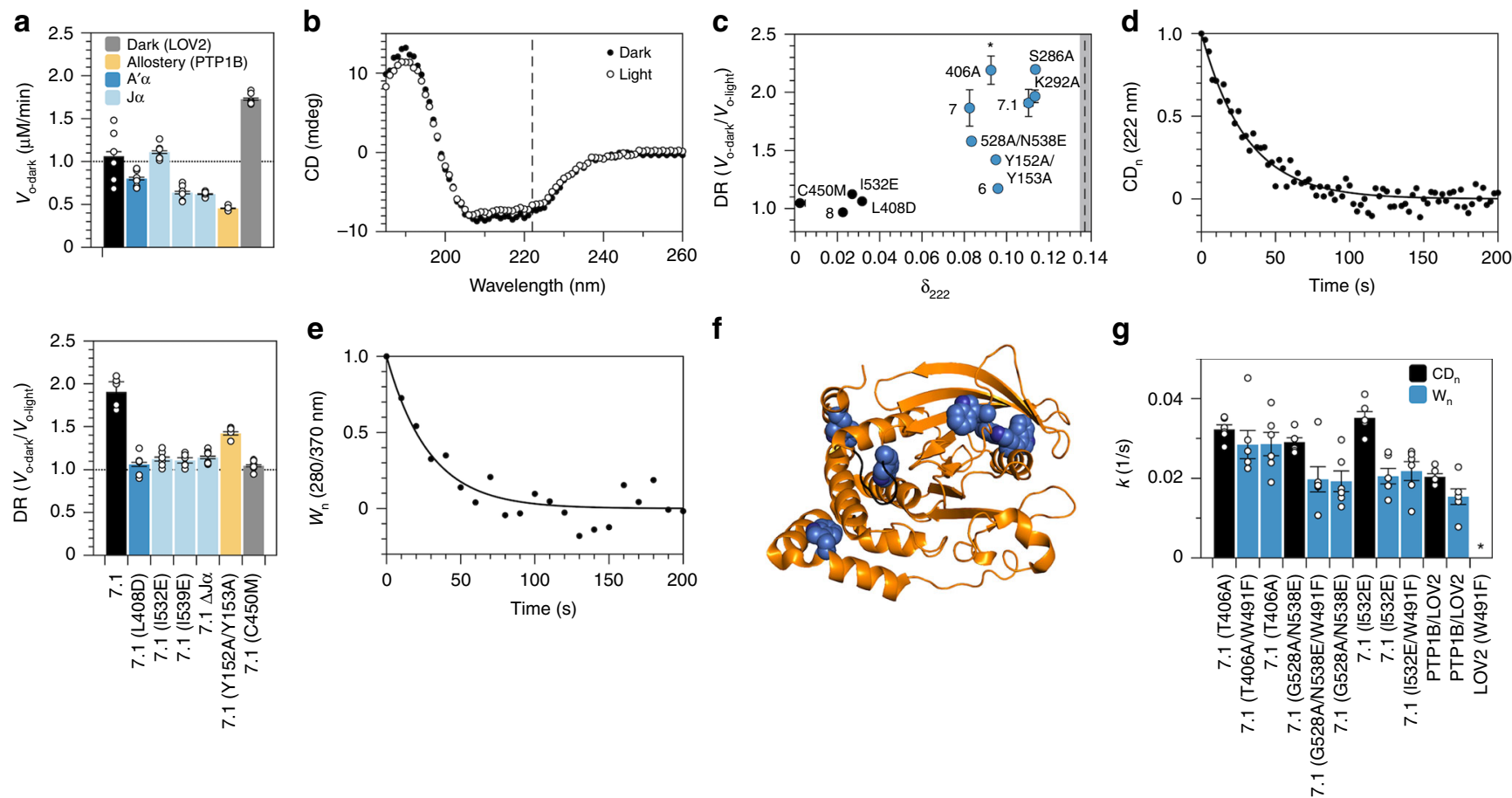

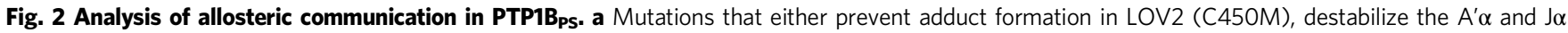
helices (I532E, I539E, and $\Delta \mathrm{J} \alpha$ ), or disrupt the allosteric network of PTP1B (Y152A/Y153A) reduce the photosensitivity of 7.1 and, with the exception of I532E and C450M, lower its specific activity. The plotted data depict the mean, $\mathrm{SE}$, and associated estimates of DR for $n=6$ independent experiments. $\mathbf{b}$ Exposure of $\mathrm{PTP}_{\mathrm{B}}$ PS to $455 \mathrm{~nm}$ light reduces its $\alpha$-helical content (i.e., the mean residue ellipticity [MRE] at $222 \mathrm{~nm}$ ). c An analysis of different chimeras indicates that

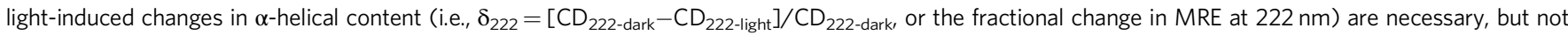
sufficient for light-sensitive catalytic activity (i.e., high DR). Mutations correspond to variants of 7.1. Chimeras with large values of $\delta_{222}$ appear in blue; the dashed line indicates $\delta_{222}$ for equimolar amounts of free PTP1B and LOV2. Error bars denote SE for $n=6$ independent reactions. d, e Thermal recovery of (d) $\alpha$-helical content (i.e., the change in MRE at $222 \mathrm{~nm}$ normalized by the full change over $250 \mathrm{~s}$ ) and (e) tryptophan fluorescence (i.e., the change in fluorescence normalized by the full change over $250 \mathrm{~s}$ ) of PTP1BPs. $\mathbf{f}$ A crystal structure of PTP1B (pdb entry 2f71) shows the locations of six tryptophan residues (blue) and the WPD loop (black). $\mathbf{g}$ Kinetic constants for thermal recovery are larger for $\alpha$-helical content than for tryptophan fluorescence (the latter of which is not affected by W491; ${ }^{*}$, unmeasurable). The discrepancy between these constants is smallest for PTP1BPS (i.e., 7.1(T406A)). The plotted data depict the mean, associated data points, and SE for $n=6$ independent reactions. Source data are provided as a Source Data file.

changes across the protein ${ }^{23,31}$. To examine the contribution of both helices to the photoresponse of chimera 7.1, one of our most light-sensitive chimeras, we introduced disruptive mutations (i.e., we added charged residues at buried sites ${ }^{31,32}$ ). For both helices, disruptive mutations reduced light-dependent catalytic activity as effectively as C450M, a "dark state" mutation that prevents the formation of the cysteine adduct in LOV2; complete removal of the Ja helix had the same effect (Fig. 2a). Our results thus indicate that both A' $\alpha$ and Ja helices are necessary for LOV2-mediated control of PTP1B activity.

A previous NMR study of PTP1B dynamics showed that mutations in its L11 loop can disrupt allosteric communication between the $\alpha 7$ helix and WPD loop ${ }^{29}$. To confirm the contribution of allostery to photocontrol, we modified chimera 7.1 with a mutation known to exert such an effect: Y152A/Y153A. This modification reduced DR by $\sim 25 \%$, a disruption distinct from the conservative/beneficial effects of alanine substitutions in the $\alpha 7$ helix (Fig. 2a). The sensitivity of DR to mutations in the L11 loop indicates that the native allosteric network of PTP1B is, indeed, necessary for optogenetic control of its catalytic activity.

We hypothesized that our most photoswitchable chimeras might exhibit large changes in secondary structure between light and dark states-changes that result largely from ordered-todisordered transitions of the A' $\alpha, J a$, and $\alpha 7$ helices. To test this hypothesis, we used circular dichroism (CD) spectroscopy to compare optically induced shifts in a-helical content
$\left(\delta_{222}=\left[\mathrm{CD}_{222 \text {-dark }}-\mathrm{CD}_{222 \text {-light }}\right] / \mathrm{CD}_{222 \text {-dark }} ;\right.$ Fig. $\left.2 \mathrm{~b}\right)$. Intriguingly, changes were large for the chimeras with light-dependent catalytic activities but spanned a range of values for low-DR constructs (Fig. 2c). The one-way dependence of DR on $\delta_{222}$ indicates that changes in $\alpha$-helical conformation are necessary, but not sufficient for photocontrol.

We speculated that chimeras with large changes in $\alpha$-helical content $\left(\delta_{222}\right)$ but light-insensitive catalytic activities (low DRs) might suffer from weak conformational coupling between the LOV2 and PTP1B domains. To study this coupling, we carried out two experiments. In the first, we examined the thermal recovery of LOV2 from the light state by illuminating PTP1BLOV2 chimeras with blue light and, subsequently, measuring the return of $\alpha$-helical content in the dark (Fig. 2d). A link between the conformation of LOV2 and $\alpha$-helical content is supported by (i) the sensitivity of $\delta_{222}$ to disruptive mutations in LOV2 and (ii) the insensitivity of $\delta_{222}$ to the catalytic response of PTP1B (that is, activity-modulating structural changes in PTP1B, which presumably differ between high- and low-DR chimeras, do not affect $\delta_{222}$ ). In the second experiment, we examined the thermal recovery of PTP1B by measuring the return of tryptophan fluorescence in the dark (Fig. 2e). A link between the conformation of PTP1B and tryptophan fluorescence is supported by (i) the existence of six tryptophan residues in PTP1B (Fig. 2f) and (ii) the insensitivity of recovery kinetics to the removal of W491, the only tryptophan in LOV2 (Fig. 2g). 
a

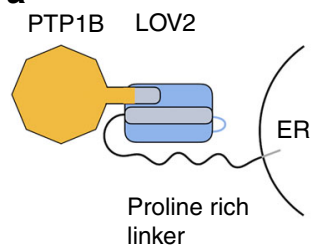

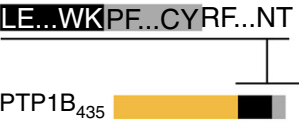

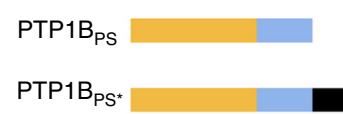

PTP1B PS
C

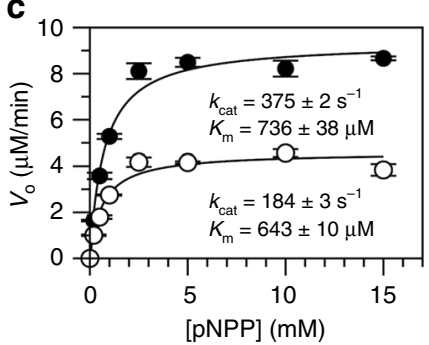

d

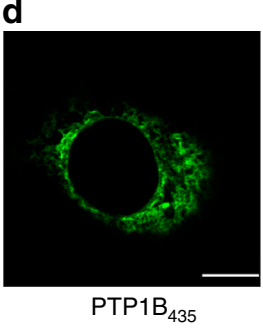

b
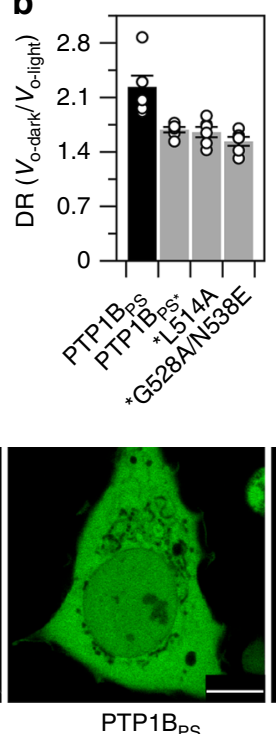
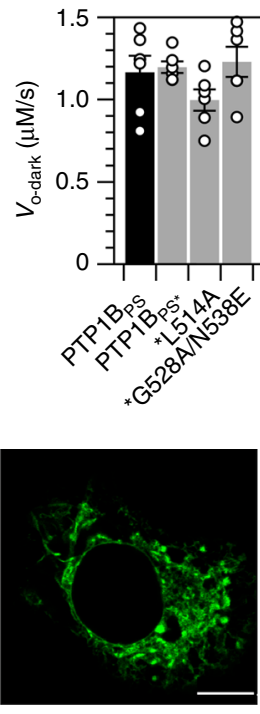

$\mathrm{PTP} 1 \mathrm{~B}_{\mathrm{PS}}$ **

Fig. 3 A natively localized variant of PTP1B $_{\mathbf{P S}}$ a We assembled PTP1B PS $^{\star}$ and PTP1B PS $^{\star \star}$ by attaching residues $299-405$ (the disordered proline-rich region) and 299-435 (the proline-rich region and ER anchor), respectively, of full-length PTP1B to the C-terminus of PTP1BPS. Colors correspond to the catalytic domain

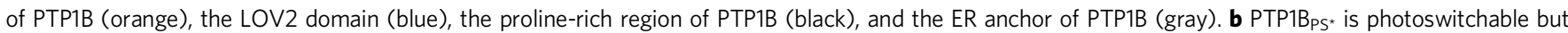

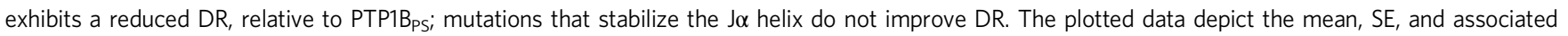
estimates of DR for $n=6$ independent experiments. c Saturation curves show the activity of PTP1BPS* on pNPP $\left(k_{\text {cat-dark }} / k_{\text {cat-light }}=2.03 \pm 0.04\right)$. Error bars denote SE for $n=3$ independent reactions. $\mathbf{d}$ Images of COS-7 cells expressing GFP-tagged variants of PTP1B. PTP1B 435 and PTP1B PS $^{\star \star}$ exhibit indistinguishable localization patterns (scale bars appear as a white line over a small black rectangle in the lower right corner of each image; $10 \mu \mathrm{m}$ ). Source data are provided as a Source Data file.

Intriguingly, kinetic constants for thermal recovery were higher for a-helical content than for tryptophan fluorescence, an indication that LOV2 reverts to its dark state more quickly than PTP1B. This discrepancy was (i) smallest for $\mathrm{PTP}_{\mathrm{B}} \mathrm{B}_{\mathrm{PS}}$, the highest-DR construct, (ii) moderate for 7.1(G528A/N538E), a construct with an intermediary DR, and (iii) largest for 7.1(I532E), a Ja-destabilized mutant without light-dependent catalytic activity (Fig. 2g). This pattern in recovery kinetics provides direct evidence that strong interdomain conformational coupling is necessary for photocontrol of PTP1B activity.

Preparation of a natively localized variant of $\mathbf{P T P}_{\mathbf{P}} \mathrm{B}_{\mathrm{PS}}$. Inside the cell, PTP1B possesses a C-terminal region-a disordered proline-rich domain followed by a short membrane anchor-that localizes it to the endoplasmic reticulum (ER; Fig. 3a) ${ }^{33}$. To examine the influence of this region on photocontrol, we attached the bulk of it (all but the hydrophobic ER anchor) to the Cterminus of $\mathrm{PTP}_{1 \mathrm{~B}}$ and assayed the extended chimera in vitro. This construct $\left(\mathrm{PTP}_{\mathrm{P}} \mathrm{B}_{\mathrm{PS}^{*}}\right)$ exhibited a reduced $\mathrm{DR}$, which was not improved by the addition of stabilizing mutations to the Ja helix (Figs. 3b, c); nonetheless, it remained photoswitchable. A construct with the full-length $\mathrm{C}$-terminus of PTP1B (everything including the ER anchor; PTP1B $\mathrm{PS}^{* *}$ ), in turn, conferred native localization in COS-7 cells (Fig. 3d).

We completed our characterization of the elongated forms of $\mathrm{PTP}_{1} \mathrm{~B}_{\mathrm{PS}}$ by examining the influence of LOV2 on interactions mediated by the disordered $\mathrm{C}$-terminal region. Briefly, we compared the susceptibilities of $\mathrm{PTP}_{1} \mathrm{~B}_{1-405}$ and $\mathrm{PTP}_{1 \mathrm{~B}} \mathrm{PS}^{*}$ to inhibition by DPM-1001, an inhibitor that binds preferentially to this region (Supplementary Fig. 5) ${ }^{34}$. To our surprise, IC $_{50}$ 's differed by $\sim 30 \%$; this small difference indicates that LOV2 does not preclude regulatory interactions with the disordered region. Importantly, DPM-1001 also binds weakly to the catalytic domain, likely by binding near the $\alpha 7$ helix ${ }^{35}$; $\mathrm{IC}_{50}$ 's for

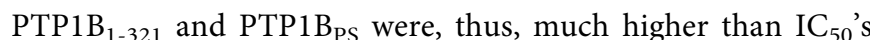
for the full-length constructs and exhibited a greater sensitivity to LOV2. This finding suggests that LOV2 may affect weak interactions that occur at its point of attachment (though, this region is not an established target for post-translational modifications).

An optogenetic probe for studying intracellular signaling. To examine the function of PTP1B-LOV2 chimeras in living cells, we sought a genetically encodable sensor for PTP1B activity. Several previously developed sensors for PTKs could plausibly support such a function; we chose a sensor for Src kinase ${ }^{36}$, an enzyme with an orthogonal activity to PTP $1 \mathrm{~B}^{37}$. This biosensor consists of an $\mathrm{SH} 2$ domain, a flexible linker, and a substrate domain (i.e., WMEDYDYVHLQG, a peptide derived from p130cas), all sandwiched between two fluorescent proteins (FPs). Src-mediated phosphorylation of the substrate domain causes it to bind to the $\mathrm{SH} 2$ domain, reducing Förster resonance energy transfer between the FPs (FRET; Fig. 4a); PTP1B-mediated dephosphorylation of the substrate domain, in turn, reverses this effect and increases FRET. To enhance the compatibility of the sensor with the blue light necessary to stimulate LOV2, we replaced CFP and YPetthe original FPs-with mClover3 and mRuby3, which have longer excitation wavelengths ${ }^{38}$. As expected, incubation of the modified sensor with Src reduced FRET and increased the donor/acceptor emission ratio; simultaneous incubation with Src and PTP1B (or Src and EDTA), by contrast, prevented this increase (Fig. 4b).

We began our imaging studies by co-expressing the biosensor with PTP1B-LOV2 chimeras in COS-7 cells. These cells are large and flat and, thus, facilitate imaging of subcellular regions ${ }^{39}$; previous studies have used them to examine PTP1B-mediated signaling events ${ }^{40,41}$. Whole-cell irradiation of cells expressing $\mathrm{PTP}_{1 \mathrm{~B}}$, with $457 \mathrm{~nm}$ light increased the biosensor signal in both the nucleus and cytosol by $\sim 7 \%$, a change larger than the $3-4 \%$ 
a

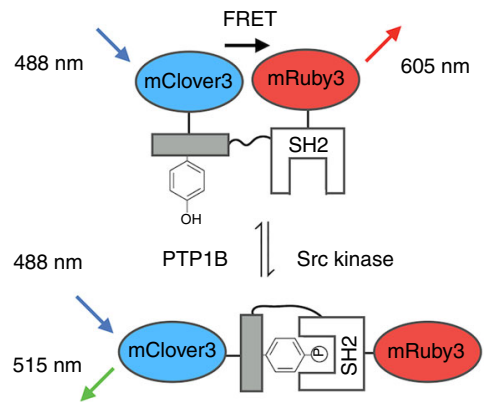

b

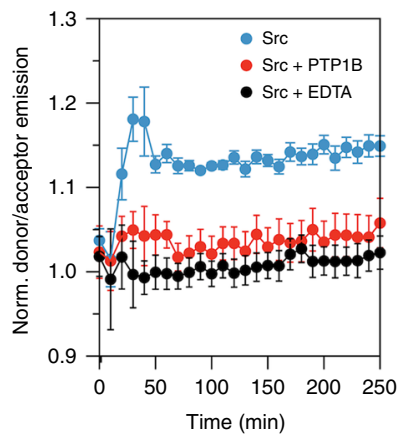

C

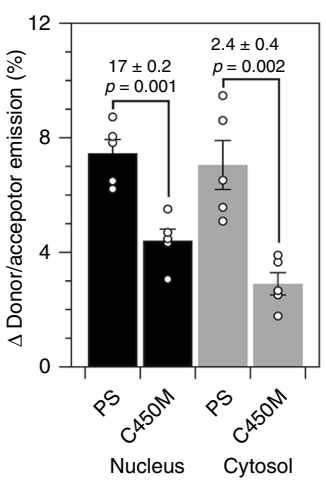

d

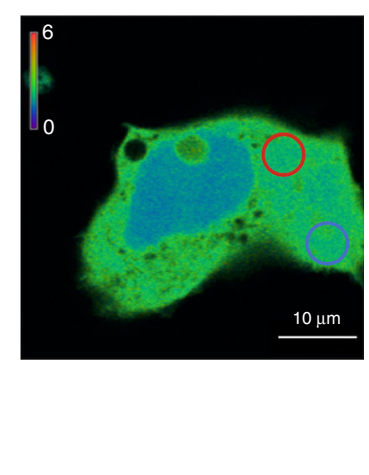

e

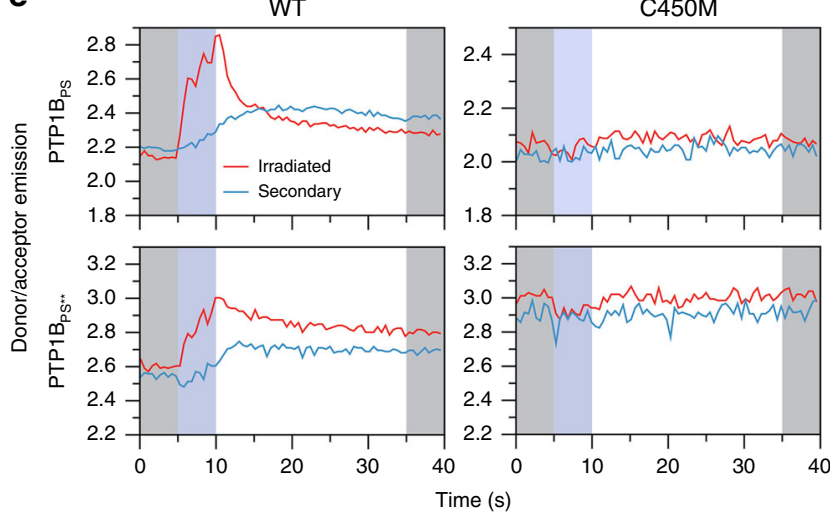

f

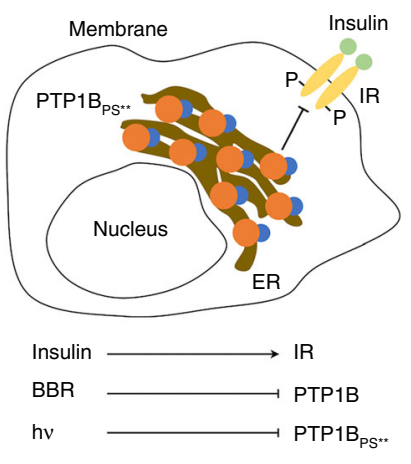

g

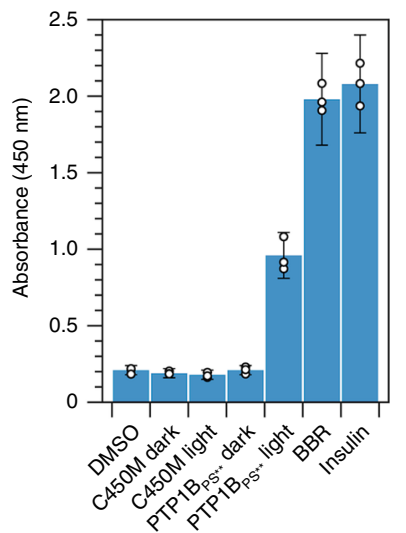

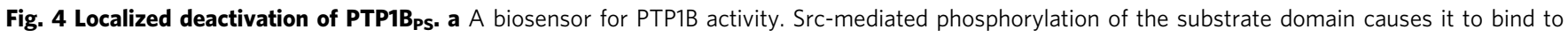
the $\mathrm{SH} 2$ domain, triggering a conformational change that decreases FRET; dephosphorylation by PTP1B increases FRET. b Src increases the donor/acceptor emission ratio in vitro (normalized by the buffer-only condition); EDTA or PTP1B prevent this increase. Error bars denote propagated SE for measurements of $n=3$ independent experiments (measurements are normalized to a to a buffer-only condition). c The percent change in donor/acceptor emission ratio over $1 \mathrm{~min}$ within $5-\mu \mathrm{m}$ circular regions located in the cytosol and nucleus of COS-7 cells activated with $457 \mathrm{~nm}$ light. Each condition includes the interquartile average, associated data points, and SE for $n=11$ biological replicates. The $p$-values correspond to a two-tailed Student's $t$ test. $\mathbf{d}$ An image of localized illumination ( $405 \mathrm{~nm}$ ) of a COS-7 cell expressing both PTP1B PS and biosensor. Circles delineate irradiated (red) and secondary (blue) regions, and colors show the donor/acceptor emission ratio (scale bar, $10 \mu \mathrm{m}$ ). e Time courses of FRET in irradiated and secondary regions. Shading highlights 5-s periods before (gray), during (blue), and after (gray) illumination. f A depiction of a HEK293T/17 cell expressing PTP1B PS $^{\star \star}$. Insulin stimulates phosphorylation of the membrane-bound insulin receptor (IR); PTP1B dephosphorylates it. $\mathbf{g}$ ELISA-based measurements of IR phosphorylation in (i) wildtype HEK293T/17 cells and (ii) HEK293T/17 cells stably expressing PTP1B PS $^{* \star}$ or PTP1B PS $^{\star *}(C 450 M)$. Insulin-mediated simulation of IR, BBR-mediated inhibition of PTP1B, and photoinactivation of PTP1B all increase IR phosphorylation. The dark state of PTP1BPS* and the dark and light states of $\mathrm{PTP}_{\mathrm{PS}^{* *}}(\mathrm{C} 450 \mathrm{M})$, by contrast, leave IR phosphorylation unaltered from its levels in the wild-type strain (DMSO). The plotted data depict the mean, propagated SE, and associated data points for measurements of $n=3$ biological replicates (relative to a buffer-only condition). Source data are provided as a Source Data file.

increase afforded by the dark-state mutant (Fig. $4 \mathrm{c}$ and Supplementary Fig. 6); the response of the biosensor in cells expressing $\mathrm{PTP}_{1} \mathrm{~B}_{\mathrm{PS}^{* *}}$, by contrast, was nearly imperceptible when compared with the dark-state analog (Supplementary Fig. 7). We note: Our imaging experiments rely on basal Src activity (i.e., we do not overexpress this enzyme). Accordingly, our findings indicate that transient inactivation of PTP1B allows background concentrations of Src to effect a rapid increase in the population of phosphorylated biosensor (other kinases could certainly contribute to this response, but our chosen biosensor is fairly specific for $\mathrm{Src}^{42}$ ).

Local irradiation of photoswitchable enzymes can permit detailed studies of spatially dependent signaling events and, by minimizing cellular exposure to optical stimuli, reduce the background signal caused by photobleaching ${ }^{10}$. To assess the compatibility of our light-sensitive chimeras with spatiotemporal studies, we used $405-\mathrm{nm}$ light to irradiate $5-\mu \mathrm{m}$ circular regions within COS-7 cells, and we measured the response of the biosensor (Figs. 4d, e). In cells expressing $\mathrm{PTP}_{\mathrm{B}} \mathrm{B}_{\mathrm{PS}}$, local irradiation of the cytosol produced a transient spike in donor/ acceptor emission ratio within the irradiated region and a modest, smooth increase in signal within a secondary region located far from the first (Fig. 4e and Supplementary Fig. 8); both irradiated and secondary regions maintained a similar increase in signal for at least $30 \mathrm{~s}$ after irradiation. In cells expressing $\mathrm{PTP}_{1} \mathrm{~B}_{\mathrm{PS}^{* *} \text {, }}$ irradiation near the nucleus produced a similar change in signal, while irradiation near the plasma membrane (PM) failed to do so (Fig. 4e and Supplementary Figs. 9-11a). In all cases, dark-state mutants produced no detectable effect. Our results thus indicate that localized inactivation of $\mathrm{PTP} 1 \mathrm{~B}_{\mathrm{PS}}$ and nucleus-proximal $\mathrm{PTP}_{1 \mathrm{~B}^{* *}}$ can produce a measurable cell-wide increase in the phosphorylation state of their targets.

The ER is a vesicular network that extends unevenly from the nucleus of the cell. To determine if the reduced activity of $\mathrm{PTP}_{1 \mathrm{PS}^{* *}}$ near the PM results from the low abundance of ER in this region, we used BFP-Sec61 $\beta$, a genetically encoded ER 
label ${ }^{43}$, to measure the subcellular distribution of ER. The fluorescence of $5-\mu \mathrm{m}$ circular regions located near the PM was 2.7-fold lower than the fluorescence of equivalently sized regions located near the nucleus (Supplementary Figs. 11b, c); this discrepancy suggests that the diffuse distribution of $\mathrm{PTP}_{1} \mathrm{BS}_{\mathrm{PS}^{* *}}$ near the PM limits its activity on membraneproximal targets.

Cells rely on complex networks of biomolecular interactions to transmit, filter, and integrate chemical signals ${ }^{44}$. The biochemical repercussions of changes in the activity of any single regulatory enzyme are, thus, difficult to assess with artificial biosensors alone. To evaluate the influence of modest changes in PTP1B activity on the phosphorylation state of a native regulatory target, we generated HEK293T/17 cells that stably express $\mathrm{PTP}_{1 \mathrm{~B}^{* *}}$ and used an enzyme-linked immunosorbent assay (ELISA) to measure shifts in IR phosphorylation caused by transient illumination $(455 \mathrm{~nm}$, $10 \mathrm{~min}$ ). To our surprise, illumination increased IR phosphorylation to levels that rivaled those elicited by high concentrations of both an allosteric inhibitor (BBR) and insulin (Fig. 4g). These optically derived shifts-which, by our best estimate, exceed a 20-fold increase over background levels (Supplementary Note 2)-did not occur in cells shielded from light or in cells stably expressing $\mathrm{PTP}_{1 \mathrm{~B}} \mathrm{PS}^{* *}(\mathrm{C} 450 \mathrm{M})$; IR phosphorylation levels in these two varieties of cells were indistinguishable from those of the wild-type cell line. Our findings thus suggest that $\mathrm{PTP}_{1} \mathrm{~B}_{\mathrm{PS}^{* *}}$ leaves native phosphorylation levels intact but enables large shifts in target phosphorylation under blue light.

\section{Discussion}

The study of PTPs has long suffered from a paucity of tools for probing and measuring their intracellular activities ${ }^{45}$. In this study, we developed a photoswitchable variant of PTP1B and used it to exert spatiotemporal control over the phosphorylation state of a genetically encoded biosensor in living cells. Transient irradiation of the full-length, natively localized construct near the nucleus but not the PM produced cell-wide changes in sensor phosphorylation. Importantly, the allosteric photocontrol system afforded shifts in activity that reach-by our best estimate $-70-85 \%$ of the maximum achievable dynamic range and match physiologically influential shifts in activity caused by post-translational modifications of PTP1B that occur outside of its active site (Supplementary Table 1). Our analysis of IR phosphorylation, in turn, suggests that modest changes in the activity of PTP1B are sufficient to effect large changes (i.e., over 20 -fold) in the phosphorylated fraction of its regulatory targets. This result, which evidences an intriguing sort of hypersensitivity, indicates that the photoswitchable variant of PTP1Bwhich unlike PTP inhibitors ${ }^{46}$, offers both exquisite selectivity and spatiotemporal precision-could provide a useful tool for biochemical analyses that rely on precise, protein-specific perturbations (e.g., imaging studies and proteomic analyses) ${ }^{47}$. Broadly, PTP1B is a therapeutic target for the treatment of diabetes, obesity ${ }^{48}$, breast cancer $^{49}$, and cardiovascular disease $\mathrm{e}^{50}$, and has emerged as a potential modulator of inflammation ${ }^{51}$, anxiety $^{52}$, immunity ${ }^{53}$, memory ${ }^{54}$, and neural specification in embryonic stem cells ${ }^{55}$; by facilitating detailed analyses of the contribution of $\mathrm{PTP} 1 \mathrm{~B}$ to these complex processes, the tools developed in this study could help to elucidate the biochemical basis-and perhaps, shared origin-of a diverse set of physiological states.

Classical-or tyrosine-specific-PTPs possess several features that are particularly incompatible with conventional approaches to optical control: Their solvent-exposed active sites are distal to both termini and, thus, difficult to obstruct with light-sensitive fusion partners ${ }^{56}$; they engage in protein-protein interactions at delocalized-and incompletely mapped-surface sites that make the physiological repercussions of domain insertion (or domain dissection) difficult to assess ${ }^{57-59}$; and their subcellular localization affects regulatory function in a non-binary manner that complicates the use of optically induced re-localization to study cell signaling 40,60 . Accordingly, future efforts to use these methods to build photoswitchable PTPs (perhaps, with higher DRs than the constructs described in this study) could be worthwhile; accompanying analyses of the influence of new control systems on protein structure, activity, and/or subcellular localization, however, will facilitate a detailed assessment of their benefits over the present system.

The results of this work offer two general insights for the design of genetically encoded probes. First, kinetic assays of PTP1B $1 \mathrm{~B}_{\mathrm{PS}}$ demonstrate that allosteric systems for photocontrol can - at least, within some classes of proteins-effect isolated changes in $k_{\text {cat }}$; such designs may be less disruptive to substrate binding (i.e., more substrate agnostic) than systems in which lightsensitive domains act as competitive inhibitors (which can be outcompeted by a sufficiently high concentrations of substrate). Future analyses of differences in the intracellular concentrations and binding affinities of regulatory targets will clarify the extent of this benefit. Second, spectroscopic analyses of PTP1B-LOV2 chimeras provide experimental evidence that strong interdomain conformational coupling can enhance allostery-derived photocontrol of one domain with another. Computational methods to optimize this coupling (e.g., methods to identify architectures that enhance correlated motions between fused domains or that reduce the dissipation of energy between them) could, thus, facilitate the development of new-and, perhaps, protein-specific -varieties of minimally disruptive control systems.

\section{Methods}

Cloning and molecular biology. We constructed PTP1B-LOV2 chimeras by fusing PTP1B and LOV2 at crossover points in a primary sequence alignment. In brief, we used EMBOSS Needle, an implementation of the Needleman-Wunsch algorithm ${ }^{61}$, to align the C-terminus of PTP1B (residues 285-305) with the N-terminus of LOV2 (residues 387-410), and we selected eight matching aligned residues as fusion points for the two domains (Fig. 1b). To assemble chimeric genes, we amplified DNA encoding PTP1B and LOV2 from pET21b and pTriEx-PA-Rac1 plasmids, respectively. (The pET21b plasmid was a kind gift from the Tonks Group of Cold Spring Harbor Laboratory; we purchased pTriEx-PA-Racl from Addgene.) We joined the two amplified segments with overlap extension PCR (oePCR; see Supplementary Table 3 for primers) and ligated the final chimeric product into pET16b for protein expression.

We generated additional constructs with standard techniques. To build singlesite mutants and truncation variants, we amplified parent plasmids with appropriate mutagenic primers (Supplementary Table 4). To construct PTP1B $\mathrm{PS}^{*}$ and $\mathrm{PTP}_{1 \mathrm{~B}^{* *}}$, we amplified C-terminal regions of PTP1B (residues 299-405 and 299-435, respectively) from pGEX-2T-PTP1B (Addgene) and used Gibson assembly to join them to the C-terminus of $\mathrm{PTP} 1 \mathrm{~B}_{\mathrm{PS}}\left(50^{\circ} \mathrm{C}\right.$ for $1 \mathrm{~h}$; see Supplementary Table 5 for primers). Finally, to construct GFP-tagged versions of

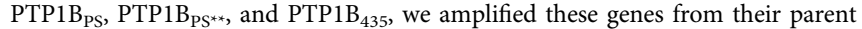
plasmids (see Supplementary Table 5 for primers) and ligated the PCR product into pAcGFP1-C1 (Clonetech, Inc.) at the NcoI and BamHI sites of the MCS for protein expression.

We developed a biosensor for PTP1B by replacing the fluorescent proteins of a biosensor for Src kinase ${ }^{36}$ with mClover 3 and mRuby $3^{38}$. In brief, we amplified DNA encoding the following components: (i) the central segment of the Src biosensor-the SH2 domain, interdomain linker, and substrate domain (i.e., WMEDYDYVHLQG, a peptide derived from p130cas) - from its parent plasmid (a Kras-Src FRET biosensor, Addgene), (ii) genes for mClover3 and mRuby 3 (plasmids pNCS-mClover3 and pNCS-mRuby3, respectively), and (iii) the backbone of pAcGFP1-C1 (Clonetech, Inc.). After amplification, we joined all segments with Gibson assembly $\left(50^{\circ} \mathrm{C}\right.$ for $1 \mathrm{~h}$; see Supplementary Table 6 for primers).

For live-cell studies, we integrated the modified biosensor and PTP1B-LOV2 chimeras into pAcGFP1-C1 by using protocols described above. In short, we amplified DNA encoding (i) $\mathrm{PTP} 1 \mathrm{~B}_{\mathrm{PS}}$ or $\mathrm{PTP}_{1} \mathrm{~B}_{\mathrm{PS}^{* *}}$, (ii) a ribosomal skipping peptide sequence (P2A-GSG, GSGATNFSLLKQAGDVEENPGP), (iii) the modified biosensor, and (iv) the pAcGFP1-C1 backbone, and we joined the segments with Gibson assembly $\left(50^{\circ} \mathrm{C}\right.$ for $1 \mathrm{~h}$; see Supplementary Tables 6 and 7 for primers and DNA fragments, respectively). 
Protein expression and purification. We overexpressed $\mathrm{PTP}_{1-281}, \mathrm{PTP}_{1-32}$, PTP1B $_{1-405}$, LOV2 ${ }_{404-547-}$, PTP-LOV2 chimeras, Src $_{251-536}$, and the modified biosensor in E. coli by carrying out the following steps: (i) We subcloned 6x polyhistidine-tagged versions of each construct into a pET16b plasmid. We positioned the tag at the N-terminus of Src and the FRET-based biosensor and the C-terminus for all other proteins. For Src, we also added a gene for Cdc37, a chaperone that facilitates protein folding in bacteria ${ }^{62}$. (ii) We transformed E. coli BL21(DE3) cells (New England Biolabs C2527) with each plasmid and spread the transformed cells onto an agar plate (25 g/L LB, $100 \mathrm{mg} / \mathrm{L}$ carbenicillin, $1.5 \%$ agar). (iii) We used one colony from each plate to inoculate a 20 -mL culture $(25 \mathrm{~g} / \mathrm{L} \mathrm{LB}$ and $100 \mathrm{mg} / \mathrm{L}$ carbenicillin), which we incubated in a shaker at $37^{\circ} \mathrm{C}$ overnight. (iv) We used the overnight culture to inoculate $1 \mathrm{~L}$ of induction media $(20 \mathrm{~g} / \mathrm{L}$ tryptone, $10 \mathrm{~g} / \mathrm{L}$ yeast extract, $5 \mathrm{~g} / \mathrm{L} \mathrm{NaCl}, 4 \mathrm{~g} / \mathrm{L} \mathrm{M} 9$ slats, $4 \mathrm{~g} / \mathrm{L}$ glucose, and $100 \mathrm{mg} / \mathrm{L}$ carbenicillin), which we incubated in a shaker at $37^{\circ} \mathrm{C}$ until it reached an $\mathrm{OD}_{600}$ of $\sim 0.6$. (v) We induced protein expression by adding $100 \mu \mathrm{L}$ of $1 \mathrm{M}$ solution of isopropyl $\beta$-D-1-thiogalactopyranoside (IPTG) to each culture and by reducing the temperature to $22^{\circ} \mathrm{C}$. (vi) At $7 \mathrm{~h}$, we pelleted cells $(3950 \times g, 20 \mathrm{~min}$; JA- 10 Beckman Coulter).

We purified all proteins with fast protein liquid chromatography. To begin, we lysed cell pellets by adding the following components to each gram of pellet: $4 \mathrm{~mL}$ of B-PER (Thermo Fisher Scientific, Inc.), $1 \mathrm{mg} \mathrm{MgSO}_{4}, 2 \mathrm{mg} \mathrm{Na}$-p-Tosyl-Larginine methyl ester hydrochloride, $1.25 \mathrm{mg}$ tris(2-carboxyethyl)phosphine (TCEP), $3.75 \mu \mathrm{l}$ phenylmethylsulfonyl fluoride, $1 \mathrm{mg}$ Lysozyme, and $10 \mu \mathrm{l}$ DNase. After mixing to homogeneity, we rocked the lysis mixtures for $1 \mathrm{~h}$ at room temperature $\left(\sim 22^{\circ} \mathrm{C}\right)$, pelleted the cell debris $(3950 \times g, 60 \mathrm{~min})$, and isolated the supernatant. To clarify the supernatant further, we added a saturated solution of ammonium sulfate to $10 \%(\mathrm{v} / \mathrm{v})$, pelleted the resulting mixture $(3950 \times \mathrm{g}, 15 \mathrm{~min})$, and used a $0.22-\mu \mathrm{m}$ filter to remove particulates. To begin purification, we exchanged the filtered supernatant into Tris- $\mathrm{HCl}$ buffer $(50 \mathrm{mM}$ Tris- $\mathrm{HCl}, 0.5 \mathrm{mM}$ TCEP, $\mathrm{pH}$ 7.5), flowed the exchanged solution over an Ni column, and eluted the protein of interest with a $0-100 \%$ gradient of imidazole $(50 \mathrm{mM}$ Tris- $\mathrm{HCl}, 0.5 \mathrm{mM}$ TCEP, $500 \mathrm{mM}$ imidazole, $\mathrm{pH}$ 7.5). For further purification, we exchanged each protein into HEPES buffer (50 mM HEPES, $0.5 \mathrm{mM}$ TCEP, $\mathrm{pH}$ 7.5), flowed the exchanged solution over an anion exchange column, and eluted the final protein with $0-100 \%$ gradient of $\mathrm{NaCl}$ ( $50 \mathrm{mM}$ HEPES, $0.5 \mathrm{mM}$ TCEP, $500 \mathrm{mM} \mathrm{NaCl}$, pH 7.5). We purchased all columns (26/10 HiPrep [desalting], HisTrap HP [Ni], and HiPrep Q HP 16/10 [anion exchange]) from GE Healthcare, Inc. We confirmed the purity of final solutions with SDS-PAGE, and we stored each protein in storage buffer (50 mM HEPES, $0.5 \mathrm{mM}$ TCEP, $20 \mathrm{v} / \mathrm{v} \%$ glycerol, $\mathrm{pH} 7.5)$ at $-80^{\circ} \mathrm{C}$.

Initial analysis of photoswitching. We screened PTP-LOV2 chimeras for lightdependent catalytic activity by measuring their activity on 4MUP in the presence and absence of light. In brief, we carried out the following steps: (i) In a room illuminated with a red light $(625 \mathrm{~nm})$, we prepared two 96 -well plates-hereafter referred to as the "light plate" and "dark plate"-with $100-\mu \mathrm{L}$ reactions consisting of buffer ( $50 \mathrm{mM}$ HEPES, $0.5 \mathrm{mM}$ TCEP, $\mathrm{pH} 7.5)$, substrate ( $500 \mu \mathrm{M}$ 4MUP), and enzyme ( $5 \mathrm{nM})$; we added a plastic cover to each plate. (ii) We encased the dark plate in foil and placed the light plate in a chamber made up of two opposing reflective steel bowls fed with a $455-\mathrm{nm}$ light $(\sim 450 \mathrm{~mW}$, SLS-0301-C, Mightex Systems, Inc.; Supplementary Figs. 1d-f). (iii) We incubated both plates at room temperature $\left(\sim 22^{\circ} \mathrm{C}\right)$. (iv) At $7,14,21,28,35$, and $42 \mathrm{~min}$ after beginning the reaction, we removed each plate from its resting position (i.e., the foil cover or light chamber), loaded it into a SpectraMax M2 plate reader, and measured the formation of 4-methylumbelliferone $\left(365_{\mathrm{ex}} / 450_{\mathrm{em}}\right)$; we immediately returned each plate to its resting position. (v) We used discrete measurements to estimate initial rates and, thus, to calculate $\mathrm{DR}$ (i.e., $\mathrm{V}_{\mathrm{o} \text {-dark }} / \mathrm{V}_{\mathrm{o} \text {-light }}$ ).

We minimized error in our measurements of photoswitching with four precautions: (i) We used concentrations of enzyme and substrate that sustained initial reaction rates for $42 \mathrm{~min}$, a length of time that minimizes the disruption of 1-min breaks required to measure product formation. (ii) For each construct in each plate, we prepared two sets of three compositionally identical, yet differentially positioned wells; this arrangement minimizes potential contributions from nonuniform illumination. (iii) For each construct at each illumination condition, we repeated the assay at least three times, collecting a total six estimates of initial rate, each based on measurements from three wells. (iv) We established a control range: When wild-type PTP1B, which was present in each plate, exhibited a $10 \%$ difference in activity between the two plates, we discarded data from both (i.e., we assumed that differences in activity between the two plates were not caused by the presence or absence of light).

We examined the light-dependent catalytic activity of PTP1B $\mathrm{BS}_{\mathrm{PS}}$ on a phosphopeptide (DADEpYLIPQQG from EGFR) by following the aforementioned procedure with several differences: (i) We used a substrate concentration of $120 \mu \mathrm{M}$ and a total reaction volume of $40 \mu \mathrm{L}$. (ii) We added malachite green solution (Sigma-Aldrich) to stop individual reactions at 2, 4, 6, or $8 \mathrm{~min}$. (iii) We measured the formation of phosphate by using the plate reader to quantify a complex formed between orthophosphate, molybdate, and Malachite Green $\left(620_{\mathrm{abs}}\right)$; we waited until the end of our experiments (i.e., $8 \mathrm{~min}$ ) for all absorbance measurements. We note: the statistically indistinguishable DRs ( $p<0.01$, two-tailed Student's $t$ test) determined for PTP1B $\mathrm{BS}_{\mathrm{PS}}$ on substrates that require different spectrophotometric measurements (i.e., fluorescence at $450 \mathrm{~nm}$ for $4 \mathrm{MUP}$ and absorbance at $620 \mathrm{~nm}$ for a phosphopeptide) suggest that the illumination conditions used for optical measurement do not artificially depress or enhance DR.

Enzyme kinetics. We examined the influence of photomodulation on enzyme kinetics by measuring the activities of PTP1B $\mathrm{B}_{\mathrm{PS}}$ and $\mathrm{PTP} 1 \mathrm{~B}_{\mathrm{PS}^{*}}$ on $\mathrm{PNPP}$ in the presence and absence of light (i.e., we used dark and light plates as described above). Briefly, we prepared $100-\mu \mathrm{L}$ reactions consisting of buffer (50 mM HEPES, $0.5 \mathrm{mM}$ TCEP, $\mathrm{pH} 7.5)$, substrate $(0.2,0.5,1,2.5,5,10$, and $15 \mathrm{mM} \mathrm{pNPP})$, and enzyme ( $25 \mathrm{nM})$; at $4,8,12,16$, and $20 \mathrm{~min}$ after initiating the reaction, we measured the production of p-nitrophenol $\left(405_{\text {abs }}\right)$ on a SpectraMax M2 plate reader; and we used DataGraph to fit initial rates to a Michaelis-Menten model of enzyme kinetics. Final values of $k_{\text {cat }}$ and $K_{\mathrm{m}}$ reflect the mean of independent estimates determined from three Michaelis-Menten curves; error $k_{\text {cat }}$ and $K_{\mathrm{m}}$ reflects the standard error of those estimates.

We examined the inhibitory effect of DPM-1001 on PTP1B-mediated hydrolysis of pNPP as follows: (i) We carried out the aforementioned pNPP reactions in the presence of different concentrations of DPM-1001 $(0,20,40,60 \mu \mathrm{M}$ for $\mathrm{PTP}_{1-405}$ and $\mathrm{PTP}_{1 \mathrm{~B}_{\mathrm{PS}} ;} 0,100,200,400 \mu \mathrm{M}$ for $\mathrm{PTP}_{32} \mathrm{~B}_{321}$ and $\mathrm{PTP}_{1 \mathrm{PS}}$ ). (ii) We used MATLAB's "nlinfit" and "fminsearch" functions to fit (a) initial-rate measurements collected in the absence of inhibitors to a Michaelis-Menten model and (b) initial-rate measurements collected in the presence and absence of inhibitors to four models of inhibition (i.e., competitive, noncompetitive, uncompetitive, and mixed inhibition ${ }^{63}$ ). (iii) We used an F-test to compare the fits to (a) a mixed model, which has two parameters, and (b) each nested single-parameter model with the lowest sum of squared errors for a given dataset. DPM-1001 exhibited mixed inhibition for all constructs ( $p<0.01$, two-tailed Student's $t$ test). (iv) We estimated $\mathrm{IC}_{50}$ 's by using the best-fit kinetic model to determine the inhibitor concentration required to reduce initial rates by $50 \%$ on $15 \mathrm{mM}$ pNPP. This high substrate concentration minimizes the concentration dependence of $\mathrm{IC}_{50}$ 's. We used the MATLAB function "nlparci" to determine the confidence intervals of kinetic parameters and propagated those intervals to estimate the corresponding confidence on $\mathrm{IC}_{50}$ 's.

We compared the activities of PTP1B $\mathrm{B}_{1-281}$ and $\mathrm{PTP}_{1-321}$ on pNPP by using a continuous assay. Briefly, we prepared $100-\mu \mathrm{L}$ reactions consisting of buffer (50 mM HEPES, $0.5 \mathrm{mM}$ TCEP, pH 7.5), pNPP $(0.2,0.5,1,2.5,5,10$, and $15 \mathrm{mM}$ ), and enzyme $(25 \mathrm{nM})$; we measured the production of p-nitrophenol at 5 -s intervals for $270 \mathrm{~s}$ (SpectraMax M2 plate reader); we used DataGraph to fit initial rates to a Michaelis-Menten model. Final values of $k_{\text {cat }}$ and $K_{\mathrm{m}}$ reflect the mean of independent estimates determined from three Michaelis-Menten curves; error $k_{\text {cat }}$ and $K_{\mathrm{m}}$ reflects the standard error of those estimates.

Finally, we evaluated the reversibility of our LOV2-based light switch by illuminating $25 \mu \mathrm{M}$ of PTP1B $\mathrm{B}_{\mathrm{PS}}(50 \mathrm{mM}$ HEPES, $0.5 \mathrm{mM}$ TCEP, $\mathrm{pH} 7.5)$ for $10 \mathrm{~s}$ and by, subsequently, monitoring its activity on $5 \mathrm{mM}$ pNPP after $5 \mathrm{~min}$ in the dark. To minimize error, we repeated this experiment three times with seven cycles per experiment (Supplementary Fig. 2).

X-ray crystallography. We prepared crystals of $\mathrm{PTP}_{1} \mathrm{~B}_{\mathrm{PS}}$ by using hanging drop vapor diffusion. To begin, we prepared a concentrated solution of $\mathrm{PTP}_{\mathrm{B}} \mathrm{B}_{\mathrm{PS}}$ ( $\sim 400 \mu \mathrm{M}$ PTP1B $\mathrm{B}_{\mathrm{PS}}, 50 \mathrm{mM}$ HEPES, pH 7.3) and a crystallization solution (100 mM HEPES, $200 \mathrm{mM}$ magnesium acetate, and 14\% polyethylene glycol 8000 , $\mathrm{pH}$ 7.5); we mixed the two solutions in 1:2, 1:3, and 1:6 ratios (protein: crystallization) to form 7-9 $\mu \mathrm{l}$ droplets for crystal growth; and we incubated the droplets over reservoirs filled with crystallization solution at $4{ }^{\circ} \mathrm{C}$ in the dark. Long hexagonal crystals with a yellow hue appeared after 1-3 weeks. Prior to freezing, we soaked all crystals in cryoprotectant (100 mM HEPES, $200 \mathrm{mM}$ magnesium acetate, and $25 \%$ polyethylene glycol $8000, \mathrm{pH} 7.5$ ) overnight.

We collected X-ray diffraction through the Collaborative Crystallography Program of the Berkeley Center for Structural Biology. We performed integration, scaling, and merging of XRD data with the xia2 software package, and we carried out molecular replacement with the Phenix graphical user interface, followed by one round of PDB-REDO ${ }^{64}$. The crystallographic data collected in this study are reported in Table 1.

Circular dichroism spectroscopy. We examined the influence of photomodulation on the secondary structure of PTP1B-LOV2 chimeras by using a circular dichroism spectrophotometer (Applied Photophysics Chirascan Plus) to measure optically induced changes in $\alpha$-helical content. To collect full-spectrum measurements, we incubated $0.2 \mathrm{~g} / \mathrm{L}$ solutions of each chimera $(10 \mathrm{mM} \mathrm{NaPi}, 0.5 \mathrm{mM}$ TCEP, pH 7.5) in a crystal cuvette (0.05-cm path length) for $10 \mathrm{~s}$ with/without blue light $(455 \mathrm{~nm})$ and immediately measured mean residue ellipticity (MRE) at 1-nm increments from 185 to $260 \mathrm{~nm}$. To measure thermal recovery, we began as before, but we measured MRE at $222 \mathrm{~nm}$ every $2.5 \mathrm{~s}$ for $250 \mathrm{~s}$ in the dark. We normalized the $\mathrm{CD}$ data thus gathered with Eq. (1), where $\mathrm{CD}_{t}, \mathrm{CD}_{0}, \mathrm{CD}_{250}$ represent MRE at $t$, 0 , and $250 \mathrm{~s}$, respectively; and we fit the normalized data to an equation for exponential decay (Eq. (2)). Final values of $k$ reflect the mean and standard error of values determined from fits to six data sets.

$$
\Delta \mathrm{CD}_{n}=\frac{\mathrm{CD}_{t}-\mathrm{CD}_{0}}{\mathrm{CD}_{250}-\mathrm{CD}_{0}}
$$




\begin{tabular}{|c|c|}
\hline & PTP1B $_{\text {PS }}$ (6NTP) \\
\hline \multicolumn{2}{|l|}{ Data collection } \\
\hline Space group & $P 3,21$ \\
\hline \multicolumn{2}{|l|}{ Cell dimensions } \\
\hline$a, b, c(\AA)$ & $89.254,89.254,105.747$ \\
\hline$\alpha, \beta, \gamma\left(^{\circ}\right)$ & $90.000,90.000,120.000$ \\
\hline Resolution $(\AA)^{a}$ & $52.87-1.89(1.92-1.89)$ \\
\hline$R_{\text {merge }}{ }^{a}$ & $0.071(2.550)$ \\
\hline$R_{\text {pim }}{ }^{a}$ & $0.025(0.893)$ \\
\hline$<l / \sigma(I)>^{a}$ & $17.2(1.1)$ \\
\hline $\mathrm{CC}_{1 / 2}^{\mathrm{a}}$ & $1.000(0.626)$ \\
\hline Completeness (\%) & $100.0(100.0)$ \\
\hline Multiplicitya & $9.0(9.1)$ \\
\hline \multicolumn{2}{|l|}{ Refinement } \\
\hline Resolution $(\AA)$ & $44.67-1.89$ \\
\hline No. reflections & 37270 \\
\hline$R_{\text {work }} / R_{\text {free }}$ & $0.17922 / 0.21175$ \\
\hline \multicolumn{2}{|l|}{ No. atoms } \\
\hline Protein & 2351 \\
\hline Ligand/ion & 1 \\
\hline Water & 224 \\
\hline \multicolumn{2}{|l|}{$B$-factors } \\
\hline Protein $b$ & 21.7 \\
\hline Ligand/ion ${ }^{b}$ & 50.8 \\
\hline Water ${ }^{b}$ & 47.4 \\
\hline \multicolumn{2}{|l|}{ R.m.s. deviations } \\
\hline Bond lengths $(\AA)$ & 0.008 \\
\hline Bond angles $\left(^{\circ}\right)$ & 1.488 \\
\hline
\end{tabular}

a $V$ alues in parentheses are for highest-resolution shell. We examined one crystal. bValues correspond to means of $B$-factors for the indicated atoms.

$$
\Delta \mathrm{CD}_{n}=e^{-k t}
$$

Fluorescence spectroscopy. To examine the influence of photomodulation on the conformation of PTP1B within PTP1B-LOV2 chimeras, we use fluorescence spectroscopy to measure optically induced changes in tryptophan fluorescence. In brief, we prepared $60 \mu \mathrm{M}$ solutions of protein (50 mM HEPES, $0.5 \mathrm{mM}$ TCEP, pH 7.5) in a Helma ultra-micro quartz cuvette (Thomas Scientific, Inc.); we illuminated those solutions for $10 \mathrm{~s}$ with a $455-\mathrm{nm}$ light; and we monitored fluorescence $\left(280_{\mathrm{ex}} /\right.$ $365_{\mathrm{em}}$ ) in 10-s intervals for $200 \mathrm{~s}$ using a SpectraMax M2 plate reader. We normalized the fluorescence data, thus gathered, with Eq. (3), where $W_{t}, W_{0}$,

$$
\begin{gathered}
W_{n}=\frac{W_{t}-W_{0}}{W_{250}-W_{0}} \\
W_{n}=e^{-k t}
\end{gathered}
$$

$W_{250}$ represent the emission at $t, 0$, and $250 \mathrm{~s}$, respectively; and we fit the normalized data to an equation for exponential decay (Eq. (4)). Final values of $k$ reflect the mean and standard error of values determined from fits to six datasets.

Biosensor development. We assessed the sensitivity of an Src biosensor ${ }^{36}$ to the activity of PTP1B by incubating it with Src in the presence and absence of PTP1B. We prepared $100-\mu \mathrm{L}$ reactions consisting of $2 \mu \mathrm{M}$ biosensor and $300 \mathrm{nM}$ Src kinase in $1 \mathrm{X}$ kinase buffer A (Thermo Fisher Scientific, Inc.) supplemented with $2 \mathrm{mM}$ DTT, $2 \mathrm{mM} \mathrm{MgCl}_{2}$, and $50 \mu \mathrm{M}$ ATP. For a subset of reactions, we added PTP1B and EDTA at concentrations of $100 \mathrm{nM}$ and $50 \mathrm{mM}$, respectively. For each reaction, we monitored the fluorescence of mClover3 $\left(475_{\mathrm{ex}} / 520_{\mathrm{em}}\right)$ and mRuby 3 $\left(475_{\mathrm{ex}} / 600_{\mathrm{em}} \mathrm{nm}\right)$ in 10 -min increments for $300 \mathrm{~min}$ on a Spectramax M2 plate reader.

Preparation of cells for imaging experiments. For live-cell imaging experiments, we grew COS-7 cells (ATCC CRL-1651, seeded from a freezer stock) in DMEM media supplemented with $10 \%$ FBS, 100 units/ml penicillin, and 100 units $/ \mathrm{ml}$ streptomycin for $\sim 24 \mathrm{~h}$ to achieve $70-90 \%$ confluency, and we seeded them on a 20-mm glass-bottom cell culture dish (MatTek). At 10-20 h after seeding, we depleted endogenous PTP1B by transfecting the cells with $25 \mathrm{nM}$ of a PTP1B siRNA silencer (AM16794, Thermo Fisher Scientific, Inc.), $12.5 \mu \mathrm{l}$ Dharmafect, and
$10 \%$ FBS. At $5 \mathrm{~h}$ after adding siRNA, we washed cells with $1 \mathrm{X}$ PBS buffer, replaced this buffer with DMEM media supplemented as above (with FBS and antibiotic), and transfected the cells with $2000 \mathrm{ng}$ of plasmid DNA and $6 \mu \mathrm{l}$ of Lipofectamine 2000 reagent (Invitrogen) according to the manufacturer's protocols. At 10-12 h after transfection with plasmid DNA, we imaged the cells in Opti-MEM media at $37^{\circ} \mathrm{C}$.

Confocal microscopy. We carried out all imaging experiments with a $\times 1001.45$ NA oil objective on a Nikon A1R confocal scanning microscope supplemented with an environmental chamber $\left(37^{\circ} \mathrm{C}, 75 \%\right.$ humidity, and $5 \% \mathrm{CO}_{2}$; Pathology Devices, Inc.). To localize both GFP-tagged PTP1B-LOV2 chimeras and BFPSec61 $\beta$, we illuminated Cos-7 cells with a $488-\mathrm{nm}$ laser $\left(0.57 \mathrm{~mW} / \mu \mathrm{m}^{2}\right.$ with a pixel dwell time of $2.2 \mu \mathrm{s}$ ) and imaged them with a $525 / 50 \mathrm{~nm}$ bandpass filter. The plasmid bearing BFP-Sec61 $\beta$ (pTagBFP-C1) was a kind gift from the lab of Gia Voeltz of the University of Colorado, Boulder.

For whole-cell activation studies, we illuminated individual cells with a $457-\mathrm{nm}$ laser focused over the breadth of the cell $\left(0.14 \mathrm{~mW} / \mu \mathrm{m}^{2}\right.$ with a pixel dwell time of $4.8 \mu \mathrm{s})$. To examine the photoresponse of the biosensor after activation, we illuminated the field of view with a $488 \mathrm{~nm}$ laser $\left(0.57 \mathrm{~mW} / \mu \mathrm{m}^{2}\right)$ and imaged the entire cell with 525/50 $\mathrm{nm}$ and 600/50 nm bandpass filters for $1 \mathrm{~min}$ (resonant scanning mode with 518.1-ms frame time). We estimated the average change in donor/acceptor emission ratio between 0 and $60 \mathrm{~s}$ after activation by calculating the interquartile average of measurements from 11 individual cells.

For localized activation studies, we focused 405-nm light over 5 - $\mu \mathrm{m}$ circular regions $\left(0.49 \mathrm{~mW} / \mu \mathrm{m}^{2}\right.$ with a pixel dwell time of $\left.4.8 \mu \mathrm{s}\right)$ and imaged the photoresponse of the biosensor by illuminating at $488 \mathrm{~nm}\left(0.57 \mathrm{~mW} / \mu^{2} ; 480 /\right.$ $30 \mathrm{~nm}$ excitation filter) and imaging with $525 / 50 \mathrm{~nm}$ and $600 / 50 \mathrm{~nm}$ bandpass filters for $1 \mathrm{~min}$. We estimated the average change in donor/acceptor emission ratio within circular regions, in turn, by calculating the difference in 5 -s averages starting (i) $5 \mathrm{~s}$ before activation and (ii) $35 \mathrm{~s}$ after activation; final estimates of changes in donor/acceptor emission reflect the mean and standard error from six independent measurements (i.e., six individual cells).

The 488-nm light used to image our FRET-based biosensor could plausibly stimulate LOV2, which absorbs at $488 \mathrm{~nm}$ (although less so than at 405 and $457 \mathrm{~nm})^{65}$. The results of Fig. 4e, however, indicate that such activation does not occur. In brief, irradiation with $405-\mathrm{nm}$ light causes a transient increase in FRET signal for cells expressing $\mathrm{PTP}_{1} \mathrm{~B}_{\mathrm{PS}}$ and $\mathrm{PTP} 1 \mathrm{~B}_{\mathrm{PS}^{* *}}$, but not for cells expressing light-insensitive analogs of these two constructs; accordingly, 488-nm light does not activate LOV2 (at least, no fully) under our imaging conditions (if it did so, irradiation at $405 \mathrm{~nm}$ would not elicit further activation). The insensitivity of LOV2 to 488 -nm light likely results from both (i) the low extinction coefficient of LOV2 at $488 \mathrm{~nm}$ and (ii) the insufficient combination of power and pixel dwell time of the 488-nm laser.

Preparation of cells for ELISA. We prepared HEK293T/17 cells (ATCC CRL11268) stably expressing $\mathrm{PTP}_{\mathrm{B}} \mathrm{B}_{\mathrm{PS} * *}$ or $\mathrm{PTP}_{\mathrm{P}} \mathrm{B}_{\mathrm{PS}}(\mathrm{C} 450 \mathrm{M})$ by following standard protocols. In brief, we grew the cells in $75 \mathrm{~cm}^{2}$ culture flasks (Corning) with DMEM media supplemented with $10 \%$ FBS, 100 units/ml penicillin, and 100 units $/ \mathrm{ml}$ streptomycin. When cells achieved $60-80 \%$ confluency, we transfected them with (i) $2000 \mathrm{ng}$ of plasmid DNA (pAcGFP1-C1 with PTP1B PS** $^{*}$ or $\mathrm{PTP}_{1 \mathrm{~B}^{* *}}(\mathrm{C} 450 \mathrm{M})$, but no GFP) linearized with the ApaLI restriction enzyme (New England Biolabs) and (ii) $6 \mu \mathrm{l}$ of Lipofectamine 2000 reagent (Invitrogen) according to the manufacturer's protocols. We passaged the cells in our growth media (as above) supplemented with $1.5 \mu \mathrm{g} / \mathrm{mL}$ puromycin, and we replaced the media every day for 10 days. We passaged the cells seven times before freezing them for further use.

ELISA of insulin receptor phosphorylation. We examined IR phosphorylation in HEK293T/17 cells exposed to various conditions by using an enzyme-linked immunosorbent assay (ELISA). To begin, we used siRNA to deplete cells stably expressing $\mathrm{PTP} 1 \mathrm{~B}_{\mathrm{PS}^{* *}}$ or $\mathrm{PTP} 1 \mathrm{~B}_{\mathrm{PS}^{* *}}(\mathrm{C} 450 \mathrm{M})$ of endogenous PTP1B (see above) and starved all cells for $48 \mathrm{~h}$ with FBS-free media. After starvation, we exposed cells to one of several conditions for $10 \mathrm{~min}$ : (i) 455-nm light (we irradiated the culture flask with $\sim 450 \mathrm{~mW}$ light, SLS-0301-C, Mightex Systems, Inc.), (ii) sustained darkness (i.e., we wrapped the culture flask in aluminum foil), (iii) $300 \mu \mathrm{M}$ of BBR (3-(3,5-dibromo-4-hydroxybenzoyl)-2-ethyl-N-[4-[(2-thiazolylamino)sulfonyl] phenyl]-6-benzofuransulfonamide, Cayman Chemical), an allosteric inhibitor of PTP1B, (iv) $10 \mathrm{nM}$ human insulin (Sigma), and (v) 1.5\% DMSO. After these perturbations, we incubated each sample with lysis buffer (Cell Signaling Technology) supplemented with $1 \mathrm{X}$ halt phosphatase inhibitor cocktail and $1 \mathrm{X}$ halt protease inhibitor cocktail (Thermo Fisher Scientific) for $10 \mathrm{~min}$, spun the cells down, and measured IR phosphorylation by using the PathScan ${ }^{\circledR}$ Phospho-Insulin Receptor $\beta$ (panTyr) Sandwich ELISA Kit (Cell Signaling Technology; \#7082).

We carried out the ELISA by using the manufacturer's prescribed steps: (i) We diluted the entirety of each lyophilized antibody-a detection antibody (phosphotyrosine mouse detection mAb; \#12982) and a secondary detection antibody (anti-mouse IgG, HRP-linked antibody; \#13304) - into $11 \mathrm{ml}$ of antibodyspecific diluent (detection antibody diluent; \#13339; HRP diluent; \#13515). (ii) We used lysis buffer to dilute each sample of cell lysate to $30 \mathrm{mg} / \mathrm{ml}$ total protein (based 
on absorbance at $280 \mathrm{~nm}$ ). (iii) We prepared $100 \mu \mathrm{L}$ of $1 \mathrm{X}, 2 \mathrm{X}, 4 \mathrm{X}$, and $8 \mathrm{X}$ dilutions of lysate from each sample (1X corresponds to no dilution, $2 \mathrm{X}$ corresponds to a 1:1 dilution in lysis buffer and cell lysate, and so on), and incubated each $100-\mu \mathrm{L}$ sample in a single well of an antibody-coated 96-well plate (insulin receptor $\beta$ rabbit mAb coated microwells; \#18872) at $4{ }^{\circ} \mathrm{C}$ overnight. (iv) We washed the cells four times with $200 \mu \mathrm{L}$ of $1 \mathrm{X}$ wash buffer and incubated the washed cells with $100 \mu \mathrm{L}$ of detection antibody at $37^{\circ} \mathrm{C}$ for $1 \mathrm{~h}$. (v) We washed the cells four times as before and incubated the cells with $100 \mu \mathrm{L}$ of HRP-linked secondary antibody solution at $37^{\circ} \mathrm{C}$ for $30 \mathrm{~min}$. (vi) We washed the cells four times and incubated them with $100 \mu \mathrm{L}$ of TMB substrate at $37^{\circ} \mathrm{C}$ for $10 \mathrm{~min}$. (vii) We added $100 \mu \mathrm{L}$ of STOP solution and measured absorbance at $450 \mathrm{~nm}$ using SpectraMax M2 plate reader.

Statistical analysis. We used an F-test to compare one- and two-parameter models of inhibition to one another. For all other analyses, we determined statistical significance by using a two-tailed Student's $t$ test.

Reporting summary. Further information on research design is available in the Nature Research Reporting Summary linked to this article.

\section{Data availability}

The source data underlying Figs. 1c, 1e, 1f, 2a, 2b, 2c, 2d, 2e, 2g, 3b, 3c, 4b, 4c, 4e, and 4g and Supplementary Figures 1b, 1c, 4a, 4c, 5b, 5c, 5d, 6b, 7b, 8c, 8d, 9c, 9d, 10c, 10d, 11a, $11 \mathrm{c}, 12 \mathrm{a}$, and $12 \mathrm{~b}$ are provided as a Source Data file; this data includes exact sample sizes for each dataset. For clarity, Supplementary Data 1-8 also group data by type (photoswitching experiments, kinetic analyses, FRET-based studies, etc.). The crystal structure determined in this study is available from the RCSB Protein Data Bank (PDB entry 6 ntp). Table 1 provides the refinement statistics for this structure. Plasmids harboring important genes used in this study are available from Addgene: LOV2 (pTriEx-PA-Rac1, \#22024,) full-length PTP1B (pGEX-2T-PTP1B, \#8602), and biosensor (Kras-Src FRET biosensor, \#78302). All other raw data not included in the paper are available from the corresponding author upon request.

Received: 10 September 2019; Accepted: 14 January 2020; Published online: 07 February 2020

\section{References}

1. Wray, J. et al. Inhibition of glycogen synthase kinase-3 alleviates Tcf3 repression of the pluripotency network and increases embryonic stem cell resistance to differentiation. Nat. Cell Biol. 13, 838-845 (2011).

2. Angers-Loustau, A. et al. Protein tyrosine phosphatase-PEST regulates focal adhesion disassembly, migration, and cytokinesis in fibroblasts. J. Cell Biol. 144, 1019-1031 (1999)

3. Liu, H. et al. PTP1B promotes cell proliferation and metastasis through activating src and ERK1/2 in non-small cell lung cancer. Cancer Lett. 359, 218-225 (2015).

4. Danial, N. N. \& Korsmeyer, S. J. Cell death: critical control points. Cell 116, 205-219 (2004).

5. Lessard, L., Stuible, M. \& Tremblay, M. L. The two faces of PTP1B in cancer. Biochimica et. Biophysica Acta - Proteins Proteom. 1804, 613-619 (2010).

6. Stanford, S. M. et al. Diabetes reversal by inhibition of the low-molecularweight tyrosine phosphatase. Nat. Chem. Biol. 13, 624-632 (2017).

7. Heneka, M. T., Golenbock, D. T. \& Latz, E. Innate immunity in Alzheimer's disease. Nat. Immunol. 16, 229-236 (2015).

8. Volinsky, N. \& Kholodenko, B. N. Complexity of receptor tyrosine kinase signal processing. Cold Spring Harb. Perspect. Biol. 5, a009043 (2013).

9. Kennedy, M. B. Signal-processing machines at the postsynaptic density. Science 290, 750-754 (2000).

10. Repina, N. A., Rosenbloom, A., Mukherjee, A., Schaffer, D. V. \& Kane, R. S. At light speed: advances in optogenetic systems for regulating cell signaling and behavior. Annu. Rev. Chem. Biomol. Eng. 8, 13-39 (2017).

11. Gautier, A. et al. How to control proteins with light in living systems. Nat. Chem. Biol. 10, 533-541 (2014).

12. $\mathrm{Wu}, \mathrm{Y}$. I. et al. A genetically encoded photoactivatable Rac controls the motility of living cells. Nature 461, 104-108 (2009).

13. Zhou, X. X., Fan, L. Z., Li, P., Shen, K. \& Lin, M. Z. Optical control of cell signaling by single-chain photoswitchable kinases. Science 355, 836-842 (2017).

14. Dagliyan, O. et al. Engineering extrinsic disorder to control protein activity in living cells. Science 354, 1441-1444 (2016).

15. Wang, H. et al. LOVTRAP: an optogenetic system for photoinduced protein dissociation. Nat. Methods 13, 755-758 (2016).

16. Taslimi, A. et al. Optimized second-generation CRY2-CIB dimerizers and photoactivatable Cre recombinase. Nat. Chem. Biol. 12, 425-430 (2016).
17. Bourdeau, A., Dubé, N. \& Tremblay, M. L. Cytoplasmic protein tyrosine phosphatases, regulation and function: the roles of PTP1B and TC-PTP. Curr. Opin. Cell Biol. 17, 203-209 (2005).

18. Whittier, S. K., Hengge, A. C. \& Loria, J. P. Conformational motions regulate phosphoryl transfer in related protein tyrosine phosphatases. Science 341, 899-903 (2013).

19. Cortesio, C. L. et al. Calpain 2 and PTP1B function in a novel pathway with Src to regulate invadopodia dynamics and breast cancer cell invasion. J. Cell Biol. 180, 957-971 (2008).

20. Liu, F. \& Chernoff, J. Protein tyrosine phosphatase $1 B$ interacts with and is tyrosine phosphorylated by the epidermal growth factor receptor. Biochem. J. 327, 139-145 (2015).

21. Leopold, A. V., Chernov, K. G. \& Verkhusha, V. V. Optogenetically controlled protein kinases for regulation of cellular signaling. Chem. Soc. Rev. 47, 2454-2484 (2018)

22. Chang, K. Y. et al. Light-inducible receptor tyrosine kinases that regulate neurotrophin signalling. Nat. Commun. 5, 4507 (2014).

23. Halavaty, A. S. \& Moffat, K. N- and C-terminal flanking regions modulate light-induced signal transduction in the LOV2 domain of the blue light sensor phototropin 1 from Avena sativa. Biochemistry 46, 14001-14009 (2007).

24. Levskaya, A. et al. Synthetic biology: engineering Escherichia coli to see light. Nature 438, 441-442 (2005).

25. Strickland, D. et al. Rationally improving LOV domain-based photoswitches. Nat. Methods 7, 623-626 (2010).

26. Pace, C. N. \& Scholtz, J. M. A helix propensity scale based on experimental studies of peptides and proteins. Biophys. J. 75, 422-427 (1998).

27. Cosentino, C. et al. Engineering of a light-gated potassium channel. Science 348, 707-710 (2015).

28. Buckley, A. M., Petersen, J., Roe, A. J., Douce, G. R. \& Christie, J. M. LOVbased reporters for fluorescence imaging. Curr. Opin. Chem. Biol. 27, 39-45 (2015).

29. Choy, M. S. et al. Conformational rigidity and protein dynamics at distinct timescales regulate PTP1B activity and allostery. Mol. Cell 65, 644-658 (2017)

30. Gehrig, S. et al. An engineered photoswitchable mammalian pyruvate kinase. FEBS J. 284, 2955-2980 (2017).

31. Zayner, J. P., Antoniou, C. \& Sosnick, T. R. The amino-terminal helix modulates light-activated conformational changes in AsLOV2. J. Mol. Biol. 419, 61-74 (2012).

32. Harper, S. M., Christie, J. M. \& Gardner, K. H. Disruption of the LOV-Ja helix interaction activates phototropin kinase activity. Biochemistry 43, 16184-16192 (2004).

33. Frangioni, J. V., Beahm, P. H., Shifrin, V., Jost, C. A. \& Neel, B. G. The nontransmembrane tyrosine phosphatase PTP-1B localizes to the endoplasmic reticulum via its 35 amino acid C-terminal sequence. Cell 68 , 545-560 (1992).

34. Krishnan, N., Konidaris, K. F., Gasser, G. \& Tonks, N. K. A potent, selective, and orally bioavailable inhibitor of the protein-tyrosine phosphatase PTP1B improves insulin and leptin signaling in animal models. J. Biol. Chem. 293, 1517-1525 (2018).

35. Krishnan, N. et al. Targeting the disordered $\mathrm{C}$ terminus of PTP1B with an allosteric inhibitor. Nat. Chem. Biol. 10, 558-566 (2014).

36. Ouyang, M., Sun, J., Chien, S. \& Wang, Y. Determination of hierarchical relationship of Src and Rac at subcellular locations with FRET biosensors. Proc. Natl Acad. Sci. USA 105, 14353-14358 (2008).

37. Montalibet, J. et al. Residues distant from the active site influence protein tyrosine phosphatase 1B inhibitor binding. J. Biol. Chem. 281, 5258-5266 (2006).

38. Bajar, B. T. et al. Improving brightness and photostability of green and red fluorescent proteins for live cell imaging and FRET reporting. Sci. Rep. 6, 20889 (2016).

39. Fehr, M., Lalonde, S., Lager, I., Wolff, M. W. \& Frommer, W. B. In vivo imaging of the dynamics of glucose uptake in the cytosol of COS-7 cells by fluorescent nanosensors. J. Biol. Chem. 278, 19127-19133 (2003).

40. Yudushkin, I. A. et al. Live-cell imaging of enzyme-substrate interaction reveals spatial regulation of PTP1B. Science 315, 115-119 (2007).

41. Zabolotny, J. M. et al. PTP1B regulates leptin signal transduction in vivo. Dev. Cell 2, 489-495 (2002).

42. Wang, Y. et al. Visualizing the mechanical activation of Src. Nature 434, 1040-1045 (2005).

43. Rowland, A. A., Chitwood, P. J., Phillips, M. J. \& Voeltz, G. K. ER contact sites define the position and timing of endosome fission. Cell 159, 1027-1041 (2014).

44. Barrios-Rodiles, M. et al. High-throughput mapping of a dynamic signaling network in mammalian cells. Science 307, 1621-1625 (2005).

45. Yao, Z. et al. A global analysis of the receptor tyrosine kinase-protein phosphatase interactome. Mol. Cell 65, 347-360 (2017).

46. He, R., Yu, Z., Zhang, R. \& Zhang, Z. Protein tyrosine phosphatases as potential therapeutic targets. Acta Pharmacol. Sin. 35, 1227-1246 (2014). 
47. Pan, C., Olsen, J. V., Daub, H. \& Mann, M. Global effects of kinase inhibitors on signaling networks revealed by quantitative phosphoproteomics. Mol. Cell. Proteom. 8, 2798-2808 (2009).

48. Barr, A. J. Protein tyrosine phosphatases as drug targets: strategies and challenges of inhibitor development. Future Medicinal Chem. 2, 1563-1676 (2010).

49. Bentires-Alj, M. \& Neel, B. G. Protein-tyrosine phosphatase $1 \mathrm{~B}$ is required for HER2/Neu-induced breast cancer. Cancer Res. 67, 2420-2424 (2007).

50. Thiebaut, P. A., Besnier, M., Gomez, E. \& Richard, V. Role of protein tyrosine phosphatase 1B in cardiovascular diseases. J. Mol. Cell. Cardiol. 101, 50-57 (2016).

51. Través, P. G. et al. Pivotal role of protein tyrosine phosphatase 1B (PTP1B) in the macrophage response to pro-inflammatory and anti-inflammatory challenge. Cell Death Dis. 5, e1125 (2014).

52. Qin, Z. et al. Chronic stress induces anxiety via an amygdalar intracellular cascade that impairs endocannabinoid signaling. Neuron 85, 1319-1331 (2015).

53. Shuai, K. \& Liu, B. Regulation of JAK-STAT signalling in the immune system. Nat. Rev. Immunol. 3, 900-911 (2003).

54. Fuentes, F. et al. Protein tyrosine phosphatase PTP1B is involved in hippocampal synapse formation and learning. PLoS ONE 7, e41536 (2012).

55. Matulka, K. et al. PTP1B is an effector of activin signaling and regulates neural specification of embryonic stem cells. Cell Stem Cell 13, 706-719 (2013).

56. Barr, A. J. et al. Large-scale structural analysis of the classical human protein tyrosine phosphatome. Cell 136, 352-363 (2009).

57. Li, S., Depetris, R. S., Barford, D., Chernoff, J. \& Hubbard, S. R. Crystal structure of a complex between protein tyrosine phosphatase $1 \mathrm{~B}$ and the insulin receptor tyrosine kinase. Structure 13, 1643-1651 (2005).

58. Pádua, R. A. P. et al. Mechanism of activating mutations and allosteric drug inhibition of the phosphatase SHP2. Nat. Commun. 9, 4507 (2018).

59. Bakke, J. \& Haj, F. G. Protein-tyrosine phosphatase 1B substrates and metabolic regulation. Semin. Cell Dev. Biol. 37, 58-65 (2015)

60. Eden, E. R., White, I. J., Tsapara, A. \& Futter, C. E. Membrane contacts between endosomes and ER provide sites for PTP1B-epidermal growth factor receptor interaction. Nat. Cell Biol. 12, 267-272 (2010).

61. Rice, P., Longden, L. \& Bleasby, A. EMBOSS: the european molecular biology open software suite. Trends Genet. 16, 276-277 (2000).

62. Piserchio, A., Cowburn, D. \& Ghose, R. Expression and purification of Srcfamily kinases for solution NMR studies. Methods Mol. Biol. 831, 111-131 (2012).

63. Hjortness, M. K. et al. Abietane-type diterpenoids inhibit protein tyrosine phosphatases by stabilizing an inactive enzyme conformation. Biochemistry 57, 5886-5896 (2018).

64. Friesner, Ra et al. Glide: a new approach for rapid, accurate docking and scoring. 1. Method and assessment of docking accuracy. J. Med. Chem. 47, 1739-1749 (2004).

65. Swartz, T. E. et al. The photocycle of a flavin-binding domain of the blue light photoreceptor phototropin. J. Biol. Chem. 276, 36493-36500 (2001).

\section{Acknowledgements}

This work was supported by funds provided by the National Science Foundation

(A.H. and J.M.F., award 1804897). The ALS-ENABLE beamlines are supported by the
National Institutes of Health (award P30 GM124169-01); the Nikon A1R microscope, by the NIST-CU Cooperative Agreement (award 70NANB15H226). The Advanced Light Source is a user facility sponsored by the Department of Energy's Office of Science (contract DE-AC02-05CH11231); the Advanced Light Microscopy Core is part of the BioFrontiers Institute. We thank Joe Dragavon for guidance on imaging studies and Annette Erbse for assistance with CD spectroscopy.

\section{Author contributions}

J.M.F. conceived of research. A.H. and J.M.F. designed experiments. A.H. carried out cloning, protein expression, kinetic measurements, crystal growth, spectroscopic analyses, and imaging experiments. B.S. collected X-ray diffraction data. B.S. and P.Z. provided guidance on structural refinement. A.H. and J.M.F. analyzed all data. A.H. and J.M.F. wrote the paper.

\section{Competing interests}

A.H. and J.M.F. are inventors on a PCT application that includes data from this paper This patent focuses on the use of genetically encoded systems to build biologically active agents, which include light-sensitive enzymes. J.M.F. is a co-founder and consultant of Think Bioscience, which develops therapeutics but does not currently focus on the assembly of light-sensitive enzymes. The remaining authors declare no competing interests.

\section{Additional information}

Supplementary information is available for this paper at https://doi.org/10.1038/s41467020-14567-8.

Correspondence and requests for materials should be addressed to J.M.F.

Peer review information Nature Communications thanks the anonymous reviewer(s) for their contribution to the peer review of this work.

Reprints and permission information is available at http://www.nature.com/reprints

Publisher's note Springer Nature remains neutral with regard to jurisdictional claims in published maps and institutional affiliations.

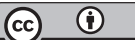

Open Access This article is licensed under a Creative Commons Attribution 4.0 International License, which permits use, sharing, adaptation, distribution and reproduction in any medium or format, as long as you give appropriate credit to the original author(s) and the source, provide a link to the Creative Commons license, and indicate if changes were made. The images or other third party material in this article are included in the article's Creative Commons license, unless indicated otherwise in a credit line to the material. If material is not included in the article's Creative Commons license and your intended use is not permitted by statutory regulation or exceeds the permitted use, you will need to obtain permission directly from the copyright holder. To view a copy of this license, visit http://creativecommons.org/ licenses/by/4.0\%

(C) The Author(s) 2020 